\title{
Effects of Monocular Visual Deprivation on Geniculocortical Innervation of Area 18 in Cat
}

\author{
Michael J. Friedlander,' Kevan A. C. Martin, ${ }^{1,2}$ and Deborah Wassenhove-McCarthy ${ }^{1}$ \\ 'Neurobiology Research Center and Department of Physiology and Biophysics, University of Alabama at Birmingham, \\ Birmingham, Alabama 35294 and ${ }^{2}$ MRC Anatomical Neuropharmacology Unit, Oxford University, Oxford, OX1 3QT, \\ United Kingdom
}

The effects of long-term monocular visual deprivation (MD) on the structure of the terminal arborizations of individual Y-type geniculocortical axons was studied in the cat's cortical area 18. Physiologically classified axons were filled with HRP by intracellular injection, and the three-dimensional distribution of the axons' terminal arborizations was quantified. Individual boutons observed at the light microscope (LM) level were verified as sites of synaptic contact by correlated light and electron microscopy (EM). Single boutons were serially sectioned and reconstructed for subsequent threedimensional analysis. The arborizations of $17 \mathrm{Y}$-axons [6 normal (N), 6 nondeprived (ND), and 5 deprived (D)] were analyzed at the LM level, and 372 boutons (104 N, 129 ND, and $139 \mathrm{D})$ were fully reconstructed from serial sections for analysis at the EM level. MD leads to an expansion in the size of ND arborizations and a variable reduction in the size of the $D$ arbors, which also have a higher bouton density than ND arborizations. ND axons form ectopic synapses, contacting proportionally more dendritic shafts than $\mathbf{N}$ or $\mathbf{D}$ boutons, and form more synapses per bouton, on average, than either $\mathbf{N}$ or $\mathrm{D}$ boutons. Compared to ND and $\mathbf{N}$ boutons, boutons of $D$ axons are smaller, have fewer mitochondria, generally form synapses on a single target (usually dendritic spines), and occasionally make no synaptic contacts.

The structural changes in the extent of individual axon arborizations may be the basis for change in ocular dominance column size with MD. However, the higher bouton density and variable effect on the extent of $D$ axon arborization size suggest that considerable geniculocortical innervation from the deprived eye remains intact. The change in target preference for ND axons suggests that instead of a direct competition for postsynaptic sites by the developing geniculocortical axons innervated by the two retinas, the ND axon arborizations expand to invade synaptic space not normally occupied in such high proportion in the normal cortex.

\footnotetext{
Received Sept. 20, 1990; revised May 28, 1991; accepted May 30, 1991.

This work was supported by NIH Grant EY-05116 to M.J.F., the UAB Neurobiology Research Center Cell Imaging Facility, NATO Grant 86/0575, and MRC and Wellcome Trust support to K.A.C.M. The software development for image reconstruction and analysis by Ms. Jill Gemmill, the technical skills of Ms. Judith Rodda, Vanessa Alones, and John Anderson, and the word-processing skills of Ms. Denise Powell, Evelyn Shearer, and Luisa Beard are gratefully acknowledged. K.A.C.M. is a Henry Head Research Fellow of the Royal Society.

Correspondence should be addressed to Dr. Michael J. Friedlander, Neurobiology Research Center, University of Alabama at Birmingham, Birmingham, AL 35294.

Copyright (C) 1991 Society for Neuroscience $0270-6474 / 91 / 113268-21 \$ 05.00 / 0$
}

The severe changes in individual boutons following MD indicate that arborization size alone is not the only structural substrate underlying the altered responses of cortical neurons; changes in synaptic distribution onto target neurons may also play a role.

It is well established in species with binocular vision that imbalances in the stimulation received by each eye during critical periods of postnatal development lead to profound and longlasting changes in the CNS (Wicsel and Hubel, 1963; Hubel and Wiesel, 1970; Olson and Freeman, 1975; Shatz and Stryker, 1978; Singer, 1978; Sherman and Spear, 1982; Wiesel, 1982; Mitchell et al., 1984; Tieman, 1985; Trotter et al., 1987; for reviews, see Sherman and Spear, 1982; Fregnac and Imbert, 1984). A particularly robust and useful model for studying these changes is monocular eyelid suture, which deprives one eye of patterned visual stimulation. Behaviorally, the animal becomes functionally blind, or amblyopic, when tested through the deprived eye (Dews and Wiesel, 1970; Sherman and Guillery, 1976; Van Hof-Van Duin, 1976; Griffin and Mitchell, 1978; Harwerth et al., 1981; Mitchell and Timney, 1981; Mitchell et al., 1984; Leigh et al., 1989). In area 17 of normal cats, $80 \%$ of cortical neurons are binocular, responding to stimulation of either eye alone. In monocularly deprived (MD) cats, less than $10 \%$ of neurons can be activated by stimulation through the deprived eye alone (Wiesel and Hubel, 1963, 1965; Shatz and Stryker, 1978). Similar shifts in ocular dominance have been shown in area 18 neurons in MD cats (Singer, 1978; M. J. Friedlander, K. A. C. Martin, and D. Wassenhove-McCarthy, unpublished observations). However, other experimental protocols, including blockade of postsynaptic inhibition (Duffy et al., 1976), enucleation of the nondeprived eye (Kratz et al., 1976), simultaneous binocular activation (Freeman and Ohzawa, 1988), or intracellular recording of synaptic responses to electrical stimulation of the optic nerve (Tsumoto and Suda, 1978), reveal the persistence of excitatory input from the deprived eye. Anatomically, in area 17, MD results in a contraction of the ocular dominance slabs formed by the afferents driven by the deprived eye, while those of the nondeprived eye expand (Hubel et al., 1977; Shatz and Stryker, 1978; Wong-Riley, 1979; LeVay et al., 1980; Kossut et al., 1983; Tumosa et al., 1989). A similar effect is seen in area 18 (Shatz and Stryker, 1978).

The functional shift in ocular dominance assessed by extracellular recordings from cortical neurons is not due to significant changes in retinal output (Sherman and Stone, 1973; but see Sur et al., 1982) or to degeneration of thalamic relay cells in the laminac of the dorsal lateral geniculate nucleus $\left(\mathrm{LGN}_{\mathrm{d}}\right)$ inner- 
vated by the deprived eye (Kalil, 1980). One hypothesis to explain the striking functional changes seen in the cortex is that an imbalance in binocular activity during a critical period of postnatal development when geniculocortical axon arborizations are normally expanding (Friedlander and Martin, 1989; Friedlander et al., 1990) and competing for synaptic space (Wiesel and Hubel, 1965) allows synaptic sites to be taken over by the geniculocortical afferents of the nondeprived eye, while the afferents from the deprived eye remain in their smaller, immature state (Friedlander and Martin, 1989; Friedlander et al., 1990). Evidence in support of this hypothesis is that there is a reduction in the territory occupied by afferents driven by the deprived eye, as assessed by transneuronal transport of tracers (Hubel et al., 1977; Shatz and Stryker, 1978; Wong-Riley, 1979; LeVay et al., 1980; Kossut et al., 1983; Tumosa et al., 1989) A further implication of this hypothesis is that the rearrangement in cortical innervation by thalamic afferents results in an amplified level of structural development for the axons and associated synapses for the nondeprived eye. Based upon our previous work (Friedlander and Martin, 1989), we would predict that, for the $\mathrm{Y}$-cell innervation to cortical area 18 in MD cats, the axons of cells innervated by the deprived eye should have smaller arborizations with a higher bouton packing density and have smaller boutons with fewer synaptic contacts located preferentially on dendritic spines as compared to axons of cells innervated by the nondeprived cyc.

Another hypothesis is that the main functional changes are due to a suppression of the inputs driven by the deprived eye, rather than a frank disconnection of their synapses. Support for this view comes from experiments in which some of the effects of MD were reversed rapidly (Duffy et al., 1976; Kratz et al., 1976; Burchfiel and Duffy, 1981; Mower et al., 1984). These data suggest that MD results in an active inhibition of the excitation from the deprived eye. Alternatively, the efficacy of excitatory synaptic transmission from the afferents of the deprived eye may be reduced (Freeman and Ohzawa, 1988; Mioche and Singer, 1989). It has been difficult to discriminate between these hypotheses with conventional anatomical methods for studying the extent of ocular dominance columns and electrophysiological methods that employ extracellular recording. Therefore, it is necessary to analyze individual axons and their associated synapses. Previous studies of the ultrastructure of populations of synapses in animals with imbalances in binocular vision (rats: Fifkova, 1970; Schwartz and Rothblat, 1980; cats: Garey and Pettigrew, 1974; Tieman, 1984, 1985) have suggested that a variety of changes in the number, size, and structure of presynaptic profiles occur in the visual cortex. However, it is not possible from these studies to infer reliably the cell type and origin of the synaptic profiles. We have used quantitative light (LM) and electron (EM) microscopic analyses of functionally identified geniculocortical axons to evaluate directly the cellular mechanisms involved in MD. We analyzed axons belonging to the same functional class that innervate cortical area 18 in normal and MD cats. Y-axons of area 18 were chosen for study for three reasons. First, this is the only area of visual cortex where the normal postnatal development of geniculocortical axon arborizations from individual physiologically identified axons has been studied at the LM and EM level in a quantitative fashion (Friedlander and Martin, 1989). Thus, abnormalities of development such as MD can be related to the normal developmental process. Second, since cortical layer 4 receives only one major functional type of $\mathrm{LGN}_{\mathrm{d}}$ input in area 18 (Y-cell input), the process of binocular competition between axons of $\mathrm{LGN}_{\mathrm{d}}$ neurons in adjacent laminae can be evaluated directly without the attendant complications of competition between other functional cell types (such as $\mathrm{X}$ - and $\mathrm{Y}$-cells) that may occur in the same layer, as it does in cortical area 17. Third, the Y-cell pathway has been shown to be particularly susceptible to visual deprivation (see Sherman and Spear, 1982, for a review).

The extent of the arborizations of individual $Y$-axons innervating cortical area 18 is strongly affected by $M D-$ the arborizations of axons driven from the nondeprived eye hypertrophy, while those driven from the deprived eye show signs of arrested development. The synaptic density is lower for the axons driven by the nondeprived eye than those driven by the deprived eye. The major effects of MD on individual boutons include changes in volume and the number and nature of postsynaptic targets - the boutons on axons driven by the nondeprived cyc are larger, contact more targets, and increase their proportion of contacts onto dendritic shafts. These findings support an alternative mechanism to that previously proposed for binocular competition at the geniculocortical synaptic level.

A preliminary account of these findings has appeared previously (McCarthy et al., 1989).

\section{Materials and Methods}

General and animal rearing. The methods for anesthesia, surgery, electrophysiological recording, cell classification, intraaxonal injection of HRP, tissue processing, and light and electron microscopic analysis of geniculocortical axons used in this study were similar to those described for the adult control experiments (Friedlander and Martin, 1989). Thus, these methods are only briefly reviewed here. MD cats were reared with normal littermates in our breeding colony at the University of Alabama at Birmingham. Monocular suture of either the left or right eyelids was performed at 6-9 d of age (just before natural eye opening) under halothane anesthesia. Suture margins were treated with topical antibiotics (Neosporin salve, Burroughs Wellcome), and kittens were returned to their mother immediately after suturing. Sutures were checked twice daily for the first 2 weeks and once daily thereafter for the presence of any signs of small openings. If openings were detected and repaired within 6-12 hr, the animals were kept for experimentation. In most cases, no resuturing was required. Control experiments were done on littermates at 5 postnatal weeks (see Friedlander and Martin, 1989) or $1 \mathrm{yr}$ of age. Other normal adult controls were reared in the breeding colony at $O x$ ford University and used as part of another study of geniculocortical axons (Freund et al., 1985a,b).

Cats were $1-4 \mathrm{yr}$ of age $(2.8-4.5 \mathrm{~kg})$ at the time of experimentation. The sutured eye was opened approximately $8 \mathrm{hr}$ before electrophysiological recordings were made. The ocular media were examined with an ophthalmoscope for any signs of opacities or scarring of the corneal surface, lens, or posterior chamber of the eye. In one of the eight MD cats reared for this study, such an opacity was observed and the animal was not used in the experiment.

The effectiveness of the monocular visual deprivation was qualitatively checked by anatomical and electrophysiological methods. During recording sessions the micropipettes traversed areas 17 and 18 of visual cortex while we searched for geniculocortical axons. Many cortical neurons were encountered with the micropipette, and their ocular dominance was noted. For all animals, the preponderance of neurons were driven exclusively from the nondeprived eye only (75-95\% of the neurons as evaluated by extracellular recording of action potentials elicited by monocular visual stimulation through each eye). Moreover, after completing the subsequent perfusion and removing visual cortex for HRP histochemistry, the $\mathrm{LGN}_{d}$ was also removed, sectioned, and stained with cresyl violet. In four cases, cell size measurements were made of adjacent binocular regions of $L \mathrm{LN}_{\mathrm{d}}$ laminae $\mathrm{A}$ and $\mathrm{A}_{1}$, and a significant cell size difference $(p<0.001$, Mann-Whitney $U$ test) was noted. In the remaining brains, the distinctively pale staining and reduced laminae size (as observed qualitatively) were observed in the A laminae innervated by the deprived eye, thus confirming the effects of MD (Hickey et al., 1977). 
A

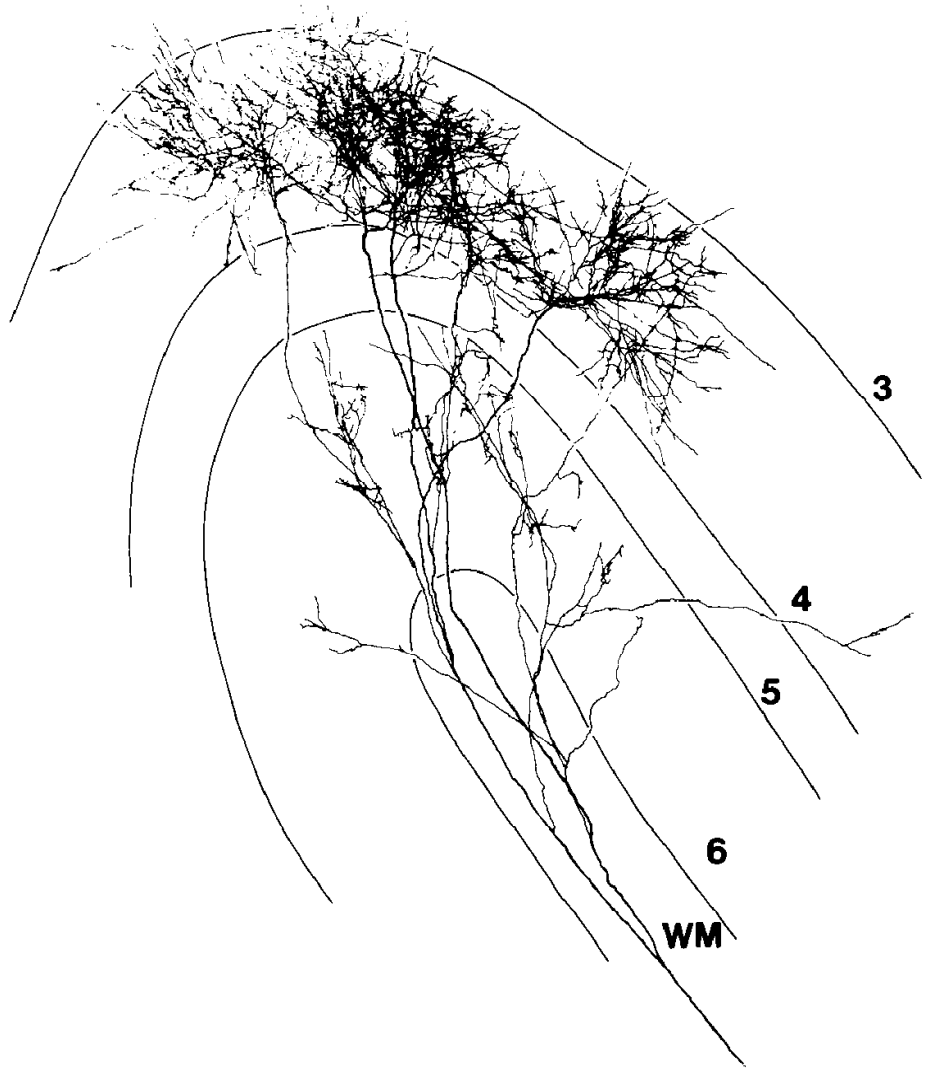

B

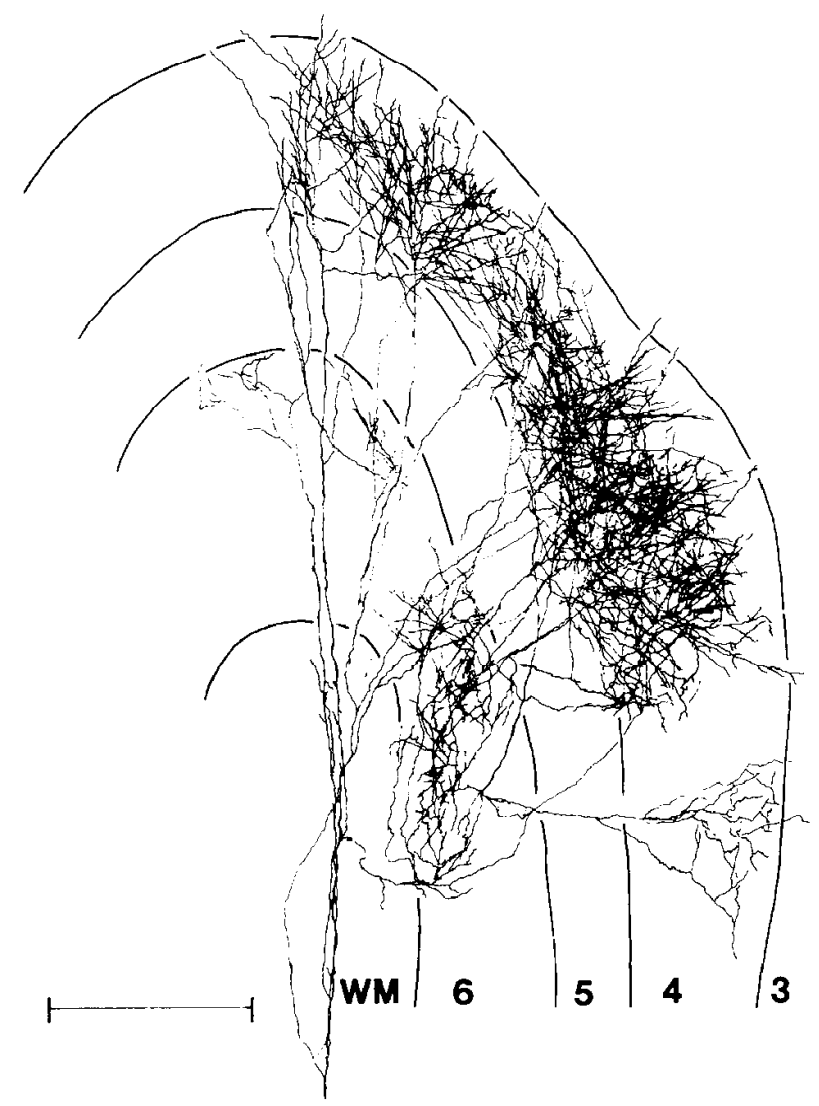

Figure 1. Reconstructions of arborizations of Y-axons from area 18 of normal $(A)$ and $\mathrm{MD}(B)$ cat. $A, \mathrm{~N} Y$-axon, off-center; RF eccentricity $=$ $13^{\circ}$. Axon was impaled with micropipette before bifurcation in white matter $(W M)$. $B$, Nondeprived eye-activated Y-axon from MD cat. Receptive field properties are similar to those of normal axon illustrated in $A$ (off-center Y-axon; RF eccentricity $=17^{\circ}$; projection to postlateral gyrus near area $17 / 18$ border). Scale bar, $500 \mu \mathrm{m}$.

Surgery. Anesthesia was initially induced with $3.0 \%$ halothane (Abbott) in a 1:1 mixturc of $\mathrm{N}_{2} \mathrm{O}: \mathrm{O}_{2}$. Surgical procedures were carricd out on a temperature-controlled blanket. The femoral vein was cannulated, the halothane was discontinued, and anesthesia for further surgical procedures was effected with alphaxalone/alphadalone (Saffan-Glaxovet) administered intravenously in a $2.4 \mathrm{mg} \mathrm{ml}^{-1}$ solution diluted in warmed physiological saline. The alphaxalone/alphadalone was administered as needed during surgery (range of doses administered, $15-20 \mathrm{mg} \mathrm{kg}{ }^{-1}$ ). The femoral artery was cannulated for continuous monitoring of blood pressure and heart rate. Mean blood pressure was kept between 90 and $120 \mathrm{~mm} \mathrm{Hg}$. Wound margins were coated with a long-lasting, oil-based local anesthetic (procaine base and butamben; Anduracaine, Reid Provident). Paralysis was effected with an initial dose of $20-40 \mathrm{mg} \mathrm{kg}^{-1}$ of gallamine triethiodide (Flaxedil, Davis and Geck), and the animals were mechanically ventilated. Inspired gases were kept at a 70:30 mixture of $\mathrm{N}_{2} \mathrm{O}: \mathrm{O}_{2}$; paralytic administration was continued throughout the experiment with an infusion pump at a rate of $12.0 \mathrm{mg} \mathrm{kg}^{-1} \mathrm{hr}^{-1}$ of Flaxedil and $0.25 \mathrm{mg} \mathrm{kg}^{-1} \mathrm{hr}^{-1}$ of $d$-tubocurarine. Alphaxalone/alphadalone (0.5$2.0 \mathrm{mg} \mathrm{kg}^{-1} \mathrm{hr}^{-1}$ ) was administered throughout the surgical procedures and during electrophysiological recording. The continuous monitoring of blood pressure and heart rate while periodically testing with ear and foot pad compression ensured that the animals remained well anesthetized. Expired $\mathrm{P}_{\mathrm{CO}_{2}}$ was monitored with a Beckman LB-II CO 2 monitor and kept between $3.8 \%$ and $4.3 \%$. Heart rate was kept below 200 beats $\mathrm{min}^{-1}$. If the animal showed any signs of stress through the remainder of the experiment (blood pressurc or heart rate increases), the 70:30 mixture of $\mathrm{N}_{2} \mathrm{O}: \mathrm{O}_{2}$ was supplemented with additional alphaxalone/alphadalone intravenously.

Optics and electrodes. Placement of contact lenses; refractions, man- ufacture, and placement of stimulating electrodes in the optic chiasm and optic radiations; and HRP-filled micropipettes for intracellular recording and labeling of geniculocortical axon arborization were as previously described (Friedlander and Martin, 1989).

Stimulus display and cell classification. Receptive fields of $\mathrm{LGN}_{\mathrm{d}}$ cell axons were initially plotted with flashing spots on a tangent screen at a viewing distance of $171 \mathrm{~cm}$. Subsequent testing was done with a Tektronix model 608 (phosphor $\mathrm{P} 31$ ) display monitor positioned at a viewing distance of $57 \mathrm{~cm}$ (screen area, $10^{\circ} \times 10^{\circ}$ ). Flashing spots or sinusoidally counterphased, spatially sinusoidal vertical gratings were generated on the display monitor by a Picasso Image Generator (Innisfree, Cambridge, MA). Axons of LGN $_{d}$ cells were tested for the following properties.

(1) Ocular dominance.

(2) Receptive field center position, size, and contrast sign.

(3) Presence of an inhibitory surround region.

(4) Linearity of spatial summation to a counterphased, vertical sinusoidal grating (mean luminance, $32 \mathrm{~cd} \mathrm{~m}^{-2}$; counterphase rate, $0.5-$ $2.0 \mathrm{~Hz}$, with spatial frequency appropriately high to reveal the second harmonic of the cell's response). Responses were considered nonlinear if the axon's modulated response had a discernable second harmonic component (see Tootle and Friedlander, 1986, 1989; Friedlander and Martin, 1989). In cases where the linearity of the cell's response was not clearly identifiable by listening, the cell's response to grating counterphase at several phase positions was collected under computer control. The summed responses over 50-100 trials were subjected to Fourier analysis. If the ratio of the second harmonic response amplitude to the fundamental amplitude was $>2.0$, the cell's response was considered nonlinear. 


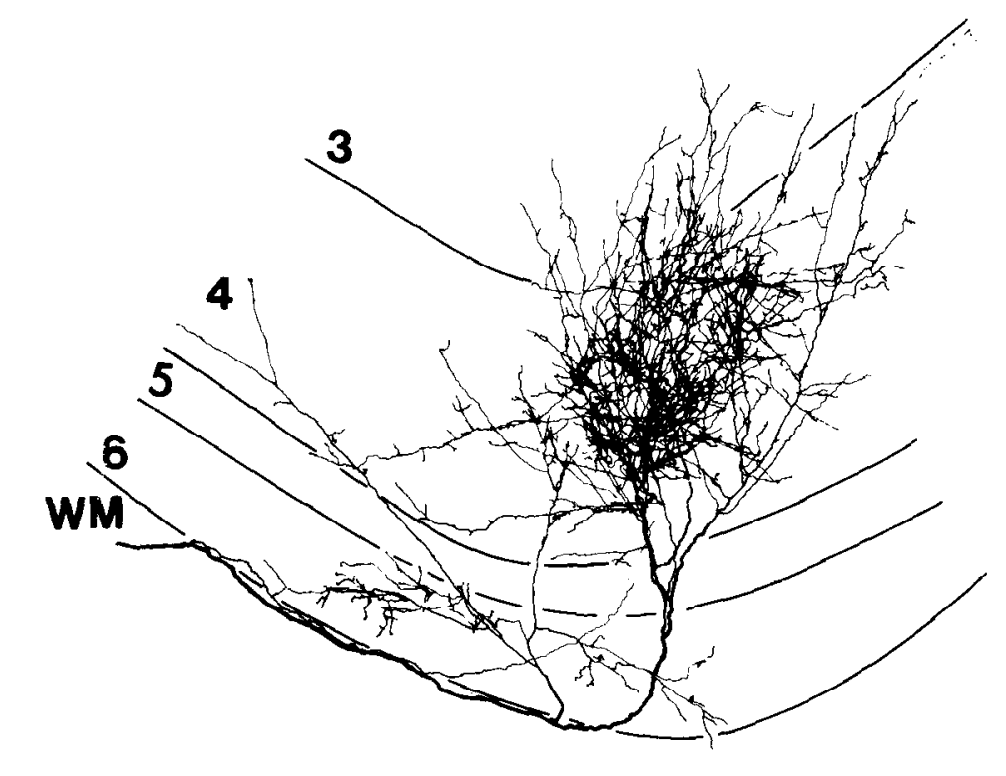

B

A

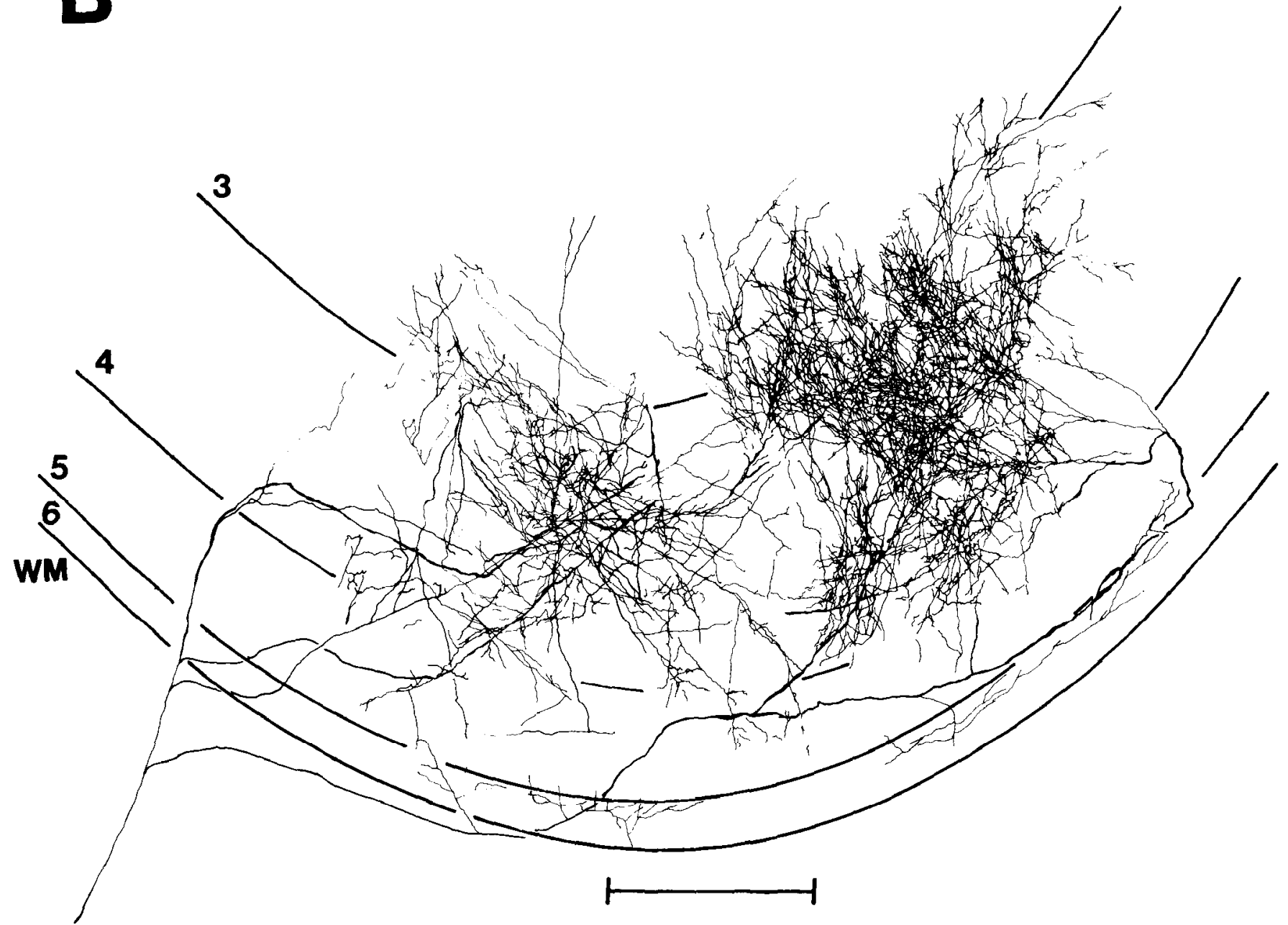

Figure 2. Reconstructions of arborizations of $\mathrm{Y}$-axons from area 18 of normal $(A)$ and $\mathrm{MD}(B)$ cat. $A, \mathrm{~N} \mathrm{Y}$-axon, off-center; RF eccentricity $=$ $9^{\circ}$ Note that considerable branching (with boutons) extends from upper layer 4 to lower layer 3 . $B$, Nondeprived eye-activated axon from MD cat. Receptive field properties and location are similar to those of the normal axon illustrated in $A$ (off-center; RF eccentricity $=11^{\circ}$; projection to the postlateral sulcus). Notc the two major clumps of the layer 4 projection and the extensive projection as compared to the normal axon. Also, note how axons that innervate the area under the sulcus enter the gray matter eccentrically. $W M$, white matter. Scale bar, $500 \mu \mathrm{m}$. 


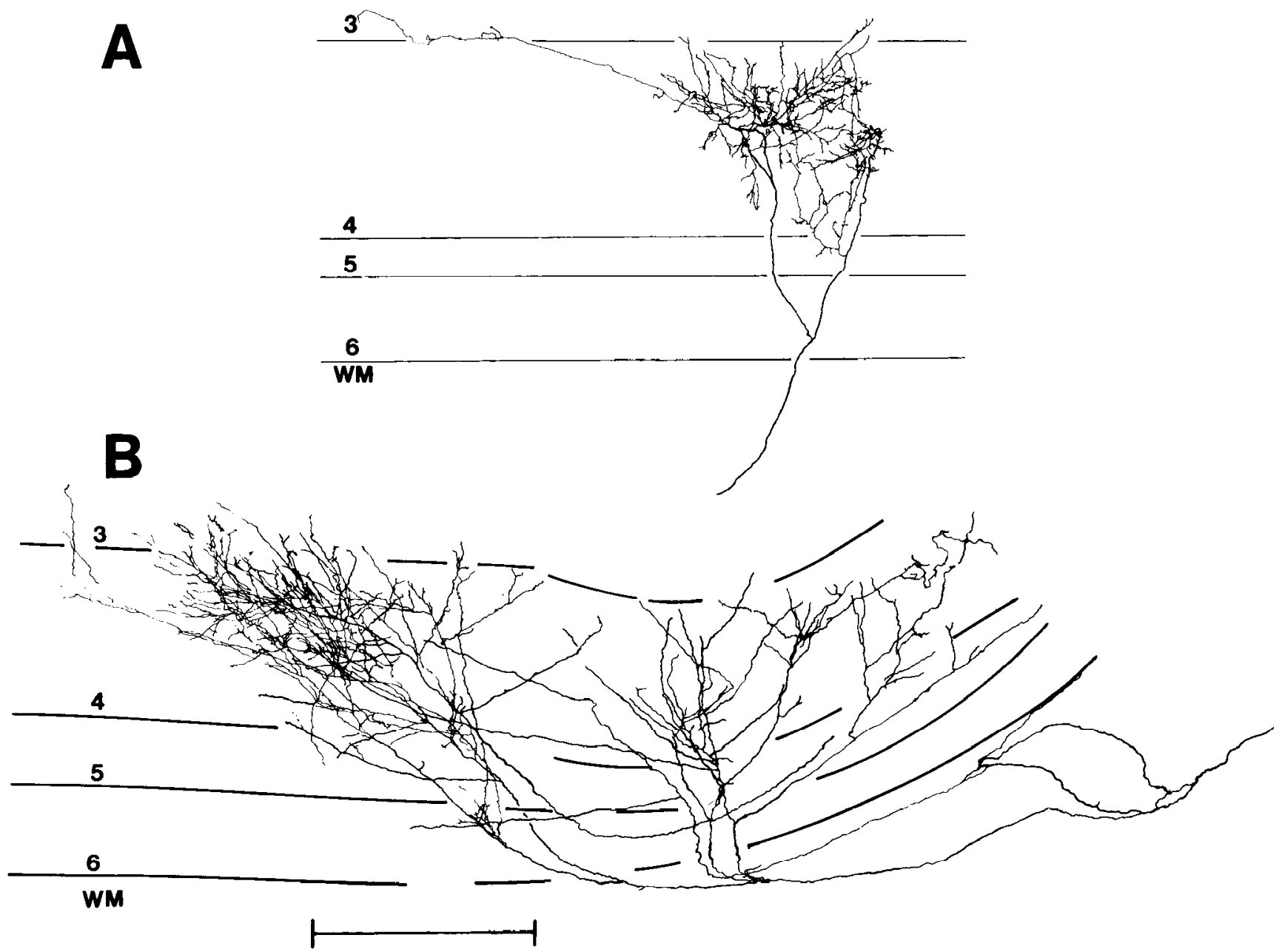

Figure 3. Reconstructions of two D Y-axons projecting to area 18. Both are on-center with RF eccentricity of $8^{\circ}(A)$ and $12^{\circ}(B)$. Note the higher magnification of this drawing (scale bar, $500 \mu \mathrm{m}$ ) compared to Figures 1-3. Both axons have "wandering branches" that stray from the main layer 4 clumping, and both have little or no innervation of layer 6 and minimal bouton spillover into layer 3 .

(5) Responsiveness to a rapidly moving ( $\left.>200 \mathrm{deg} \mathrm{sec}^{-1}\right)$ large $\left(12^{\circ}\right.$ $\left.\times 12^{\circ}\right)$ target of contrast opposite to that of the receptive field center sign.

(6) Latency to suprathreshold electrical stimulation of the optic chiasm and optic radiations at $1 \mathrm{~Hz}$.

Axons were considered to originate from $\mathrm{LGN}_{\mathrm{d}} \mathrm{Y}$-cells if they responded to grating counterphase with a phase-independent doubling response indicative of nonlinear spatial summation, their latency to electrical stimulation of the optic chiasm was $<2.0 \mathrm{msec}$ (or the optic chiasm-optic radiation latency difference when both responses were obtained was $<1.5 \mathrm{msec}$ ), and they responded reliably to high-velocity visual stimuli.

$H R P$ injection and tissue processing. After the axon had been electrophysiologically characterized as being that of an $L_{G N}$ neuron, the axolemma was penetrated with the micropipette. The intraaxonal recording condition was indicated by a membrane potential of -30 to $-70 \mathrm{mV}$. The neuron's receptive field properties were checked repeatedly throughout the intracellular recording, which lasted from 5 to 20 min on average. The axon was then filled with HRP by ionophoresis. Depolarizing current pulses of $2.0-8.0 \mathrm{nA}(200 \mathrm{msec}$ duration at 2.5 $\mathrm{Hz}$ ) were delivered from 2 to $30 \mathrm{~min}$. The micropipette was then withdrawn and a new penetration was made. Only $\mathbf{L G N}_{\mathrm{d}}$ axons that were impaled in the white matter and well filled with HRP were included in this study. The animals were deeply anesthetized with Nembutal from 2 to $24 \mathrm{hr}$ after the last axon was injected and perfused transcardially with heparinized saline followed by a modified Karnovsky's fixative ( $2.5 \%$ glutaraldehyde, $1.0 \%$ paraformaldehyde in phosphate buffer). The visual cortex was subsequently blocked in the coronal plane. Sections were cut on a Vibratome (Oxford Instruments) at $80 \mu \mathrm{m}$ and reacted for HRP activity with the catechol/ $p$-phenylene reaction method of Hanker et al. (1977) with cobalt and nickel intensification (Adams, 1981). Wet sections were examined for HRP-filled processes at $160 \times$ and were postfixed in osmium tetroxide ( $1 \%$ solution in $0.1 \mathrm{M}$ phosphate buffer for 45-60 min depending on the background darkness of HRP reaction), mounted on slides in Durcupan ACM resin (Fluka) under a coverslip, and cured for $2 \mathrm{~d}$ at $56^{\circ} \mathrm{C}$.

The thickness of osmicated sections, as measured to $0.5 \mu \mathrm{m}$ accuracy with an optical encoder on the microscope stage, was close to the original value at which it was cut $(62-75 \mu \mathrm{m}$ vs. $80 \mu \mathrm{m})$, thus facilitating our three-dimensional analysis of the structure of the axons' terminal arborizations within the visual cortex. The shrinkage factor $(6-23 \%)$ was incorporated into measurements of bouton spacing and density based on measurements of each individual section analyzed. The arborizations were drawn under oil immersion ( $40 \times$ or $50 \times$ objectives), were photographed through the light microscope, had their bouton positions digitized and reconstructed in three-dimensional space, and were reembedded for correlated serial electron microscopy of the individual boutons (see Friedlander and Martin, 1989). A double-blind procedure was used for the sectioning, photography, digitizing, and analysis of the arborizations and individual boutons.

$L M$ analysis. The HRP-filled axons were drawn from each section and reconstructed as two-dimensional montages. Axons were selected for drawing and further quantitative analysis only if HRP injections were made in the white matter, the injections were clearly into a single axon (as determined by inspection of the injection site), axonal branches were darkly filled with clearly visible boutons along their course (as viewed at $160 \times$ magnification), the HRP reaction product in branches was not seen to fade over distance, and branches could be followed 

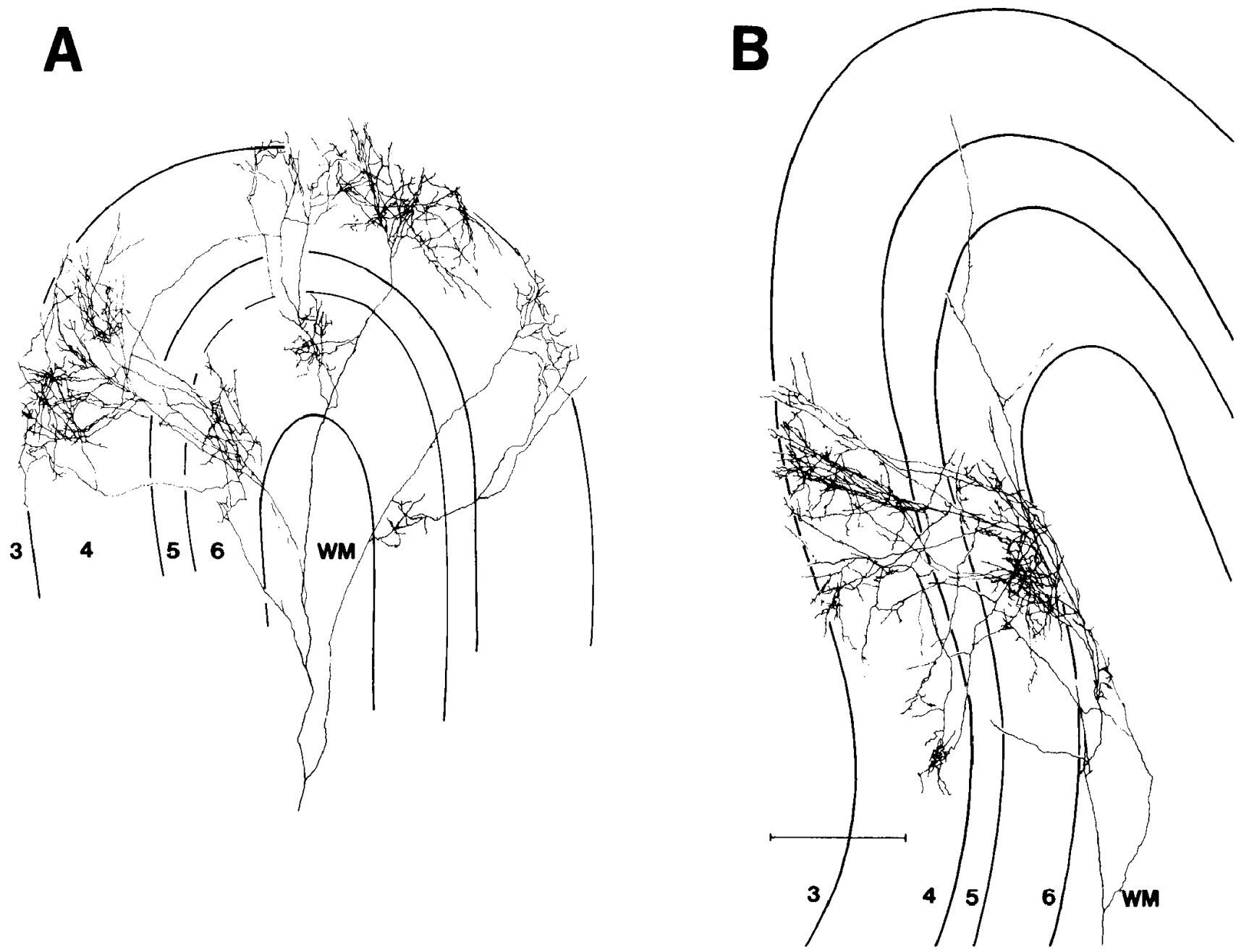

Figure 4. Reconstructions of D Y-axons projecting to areas 18 and 17. A, Example of D axon with two major bifurcations in the white matter $(W M)$ that give rise to three major clumps of boutons in upper layer 4 . Receptive field properties: off-center; $R F$ eccentricity $=19^{\circ}$. Note the layer 6 projection is in register with each arborization in layer $4 . B$, Example of $D$ axon with a number of solitary branches that issue few collaterals or boutons. Note the extensive layer 6 projection of the axon. Receptive field properties: off-center; RF eccentricity $=9^{\circ}$. Scale bar, $500 \mu \mathrm{m}$.

toward endlike structures (terminal clusters of boutons or a narrowing of the axon segment). Moreover, only axons with branches determined to be completely filled with HRP (as verified at the EM level; see below) were used in the analysis of arborization size. The extent of the boutons in layers 3 and 4 was measured by constructing surface-view drawings of their distribution in serial sections (Friedlander and Martin, 1989). The areal extent of the bouton distribution in an individual section was taken as the product of section thickness $(80 \mu \mathrm{m}$ in the anterior-posterior axis) and the extent of the layer 3 and 4 boutons in the mediolateral axis, excluding regions that were free of clumps of boutons for $\geq 100$ $\mu \mathrm{m}$. While this method is sensitive to changes in the overall extent of the arborizations, it may not detect changes in the spacing of bouton clumps. The total surface area of an arborization was expressed as the sum of these areas from the serial sections through the reconstructed length of the arborization. Location of the axons' terminal arborizations was determined according to the cytoarchitectonic criteria of Hubel and Wiesel (1965). Subdivision of cortical lamina 4 into dorsal and ventral tiers (4A and $4 B$, respectively) was according to the criteria of O'Leary (1941) and Lund et al. (1979). The lamination and cortical areal borders are readily visible in the osmicated material. The central region of the axon's innervation of layer $\mathbf{4}$ in area 18 was selected from the center of the arborization for quantitative analysis of bouton density. The axons used for quantitative analysis were well filled with HRP reaction product. By confining our quantitative measurements to the center of the arbors, the possibility of missing any boutons was reduced. This central region was approximately $1.00 \mathrm{~mm}$ wide $\times 0.50 \mathrm{~mm}$ high $\times 0.08 \mathrm{~mm}$ thick for each of thrce or four serial sections. The position of each bouton along the axonal branches in this region was digitized (at $500 \times$, resolution $=0.5 \mu \mathrm{m}$ ) with the use of software developed in our laboratory to run on a PDP $11 / 23$ computer and a microscope equipped with optical encoders to read stage position ( $x$-and $y$-axes), a digitizing tablet with a microscope drawing tube attachment to encode position within a field of view, and optical encoding of focal depth (z-axis). The distribution of the boutons was visualized from a variety of perspectives using an image rotation program developed in our laboratory that runs on a DEC VAX 11/750 computer and an Evans and Sutherland PS 300 graphics work station. The distribution of boutons in three-dimensional space was analyzed for the central region of the arborizations in layers $3 / 4$. The density of boutons was calculated for a $0.1-0.3 \mathrm{~mm}^{3}$ cube centered over the densest cortical part of the terminal arborization. The actual size of the window was set such that no stretch of $>150 \mu \mathrm{m}$ occurred in any axis that was free of boutons.

EM analysis. Correlated LM/EM was accomplished by periodically photographing and digitizing the arborizations in the block as thin sections were taken. Boutons (as viewed at the LM level) were serially sectioned and collected as ribbons on slotted grids. All quantitative analysis was carried out only on boutons that were fully serially reconstructed as evaluated by collecting full series of sections including the regions with any detectable sign of diameter change in the axon. We have previously demonstrated that boutons visualized at the LM level are sites of synaptic output as seen at the EM level (Freund et al., 1985a,b; Friedlander and Martin, 1989). However, we revalidated this relationship in MD material, and thus we also compared apparent interbouton segments of axon to LM-identified boutons. A similar rela- 

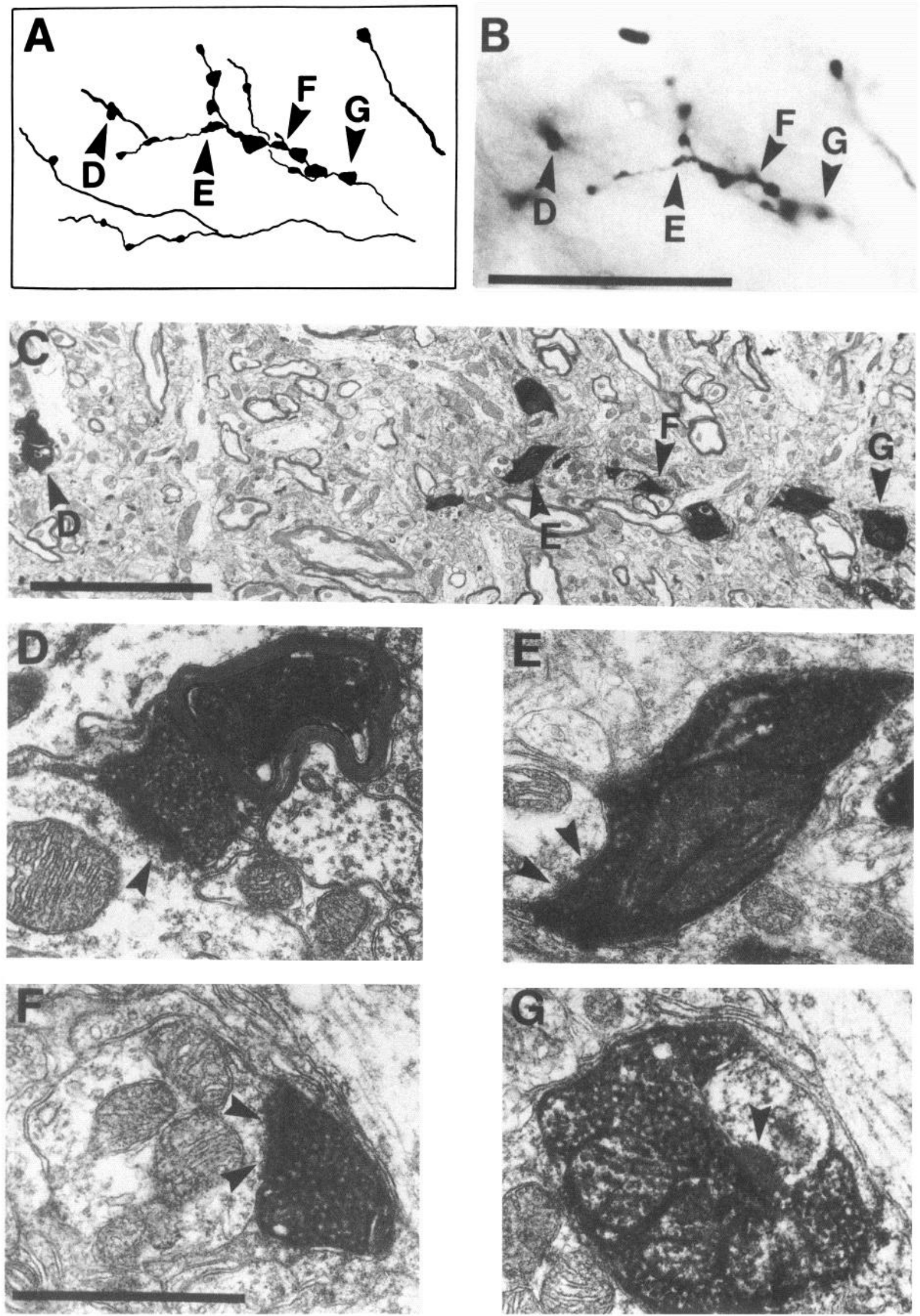

Figure 5. Correlated LM/EM analysis of boutons with sites of synaptic output on an ND Y-axon in area 18. $A$ and $B$ illustrate drawing and LM photomicrograph, respectively, of part of the arborization in upper layer 4 . The varicosities are synaptic boutons. Scale bar for $A$ and $B, 20 \mu \mathrm{m}$. 
tionship was observed in MDs: swellings identified at the LM level are generally boutons packed with mitochondria and vesicles at the EM level, while smooth stretches of interbouton segments do not have any of the ultrastructural features of presynaptic specializations.

Serial sections were photographed and printed at $5000 \times$ and 16,000×. Micrographs were examined for extent of the boutons, presence of vesicles and mitochendria, and identity of postsynaptic targets and postsynaptic densities (PSDs). A random sample of 30-100 boutons from each of 12 area $18 \mathrm{Y}$-axons was selected for quantitative analysis. Attempts were made to collect full serial sections and micrograph series of each of over 500 boutons. Full reconstructions were made of 372 of these boutons [139 from four nondeprived (ND) axons, 129 from five deprived (D) axons, and 104 from three normal (N) axons]. The boutons were fully reconstructed in three dimensions by digitizing each of from 15 to 80 serial sections. The outline of the bouton, the mitochondria contained within it, the postsynaptic densities, and often the postsynaptic target such as a dendritic spine were digitized. The identity of the postsynaptic targets was recorded. The digital reconstructions of the three-dimensional images were analyzed with software run on our VAX $11 / 750$ and displayed on an Evans and Sutherland PS 300 color graphics work station. The values of the bouton volumc, number of mitochondria and their volume, number and nature of postsynaptic targets, and area of postsynaptic densities were entered into a spread sheet for further analysis.

Statistics. Comparison of the extent and density of the axonal arborizations evaluated at the LM level was made by treating each axon as an independent observation, and rank-order comparisons were made with a Mann-Whitney U test. Similarly, various quantitative comparisons of the synaptic boutons at the EM level were made by calculating a centroid (mean or median) for the distribution of observations of all the boutons analyzed for a single axon. The centroids were treated as single observations, ranked, and compared using a one-tailed MannWhitney $U$ test to test specific hypotheses (see introductory remarks) about the structural changes that occur during MD to a population of boutons from an individual axon. However, when there was not a specific direction to the hypothesis to be tested (such as for evaluating the number of mitochondria within the deprived presynaptic terminals or the size of the postsynaptic densities for the targets of the bouton), twotailed statistical tests were used. In addition, the individual reconstructed boutons were also treated as independent observations, and the overall distributions of the various measures for the boutons were compared using $\chi^{2}$ statistics. The EM data are graphically represented with both approaches (treating each axon or each bouton as a single observation). In all cases, both types of statistical analysis were corroborative, either mutually finding or not finding significant differences.

\section{Results}

Data base. The results reported in this study were obtained from seven long-term MD and three normal adult cats. A total of 94 geniculocortical axons from the MD cats were classified based on electrophysiological criteria (see Materials and Methods), and attempts were made to impale them with micropipettes. The sample includes 66 axons activated through the nondeprived eye ( $23 \mathrm{X}$-axons, $40 \mathrm{Y}$-axons, and 3 axons with mixed input) and 28 axons activated through the deprived eye (13 $\mathrm{X}$-axons, $14 \mathrm{Y}$-axons, and 1 axon with mixed input). Forty-one of the 94 axons were successfully recorded intracellularly and had HRP ionophoresed into them for over $5 \mathrm{~min}$. Twenty-one of the 41 axons appeared to have their arbors completely filled with HRP. Seventeen of these arbors were from Y-axons that project to area 18 and were used for quantitative analysis of the LM data [6 N: 4 off-center, 2 on-center; receptive field (RF) eccentricity range, $6-18^{\circ} ; 6 \mathrm{ND}: 4$ off-center, 2 on-center; RF eccentricity range, $7-21^{\circ} ; 5 \mathrm{D}$ : 2 off-center, 3 on-center; RF eccentricity range, $\left.7-19^{\circ}\right]$. The arborizations of 12 of these axons (3 $\mathrm{N}$ axons, one each from each cat; $4 \mathrm{ND}$ axons, 2 from one MD cat and 1 each from two other MD cats; 5 D axons, 1 each from five separate MD cats, 2 of which were from the same cats from which ND axons were obtained) were also evaluated with the electron microscope. These 12 of the 17 well-filled axons were chosen for EM analysis based upon the excellent quality of the fixation for EM in this material. A total of 533 boutons from these 12 axons were studied (167 N, 229 ND, and $137 \mathrm{D})$, of which 372 were fully reconstructed from serial sections (104 N, $129 \mathrm{ND}$, and $139 \mathrm{D})$. From 23 to 42 boutons were fully reconstructed for each of the 12 axons. The results of the LM analysis of the arborizations are presented first, followed by the EM analysis of the type of postsynaptic targets for the same three groups of axons. The quantitative measurements of numbers of synaptic targets per bouton, bouton volume, mitochondrial content, and area of PSDs for the ND and D axons are presented last.

Qualitative analysis of arbors-LM. Drawings of arborizations of representative $Y$-axons from normal cats and ND axons from $\mathrm{MD}$ cats are illustrated in Figures 1 and 2, $A$ and $B$, respectively. In both figures, axons with similar receptive field properties and location (see Figs. 1, 2 captions) are compared. The overall extent of the ND axon's arborization was greater (see Fig. 7 for a quantitative comparison). Both axons had distinct clumps with a spacing of $\simeq 500 \mu \mathrm{m}$. The arborizations illustrated in Figure 2 both innervated the region of area 18 under the postlateral sulcus. In this region, the boutons concentrated loward the upper half of layer 4.

Four examples of axons from $\mathrm{LGN}_{\mathrm{d}}$ cells driven from the deprived eye are illustrated in Figures 3 and 4 . Note the variable extent of the arborizations. Typically, these axons had one or a few isolated, well-filled branches that diverge from the main bouton clumps. The bouton density within a small central region of the D arborizations in layer 4 was high (see Fig. 3), but the region they innervated was reduced compared to axons from normal animals. For the axon shown in Figure $4 A$, the overall extent of visual cortex innervated in the mediolateral axis was large (over $4.0 \mathrm{~mm}$ ). However, much of this area was comprised of large gaps between clusters of boutons. Moreover, the density of boutons from this particular axon in a volume of cortex in one of three zones was high $\left(>1 \times 10^{7}\right.$ boutons $/ \mathrm{cm}^{3}$; sce Fig. 7). For the axon in Figure $3 A$, a single clump of boutons innervated layer 4 with an overall areal extent of $<0.2 \mathrm{~mm}^{3}$.

Correlations of boutons with sites of synaptic output. In our earlier study of axons from kittens and normal adult cats, boutons identified at the LM level were a reliable indication of presynaptic sites identified at the EM level (Freund et al., 1985a,b; Friedlander and Martin, 1989). However, it was necessary to make a similar determination for axons in MD cats. Thus, we did a correlated LM/EM study of 72 boutons from two ND axon arbors and 46 boutons from two $\mathrm{D}$ axon arbors. As in the

\footnotetext{
Letters $D-G$ indicate individual boutons viewed with low- and higher-magnification electron micrograph in panels of same letter. $C$, Lowmagnification $(5000 \times)$ electron micrograph of same field of view in LM photomicrograph $B$. Scale bar, $5 \mu \mathrm{m}$. This fortuitous plane of section shows four of the boutons visible in $B$. D-F. Individual higher-magnification electron micrographs of boutons $D-G$ indicating that each is indeed a presynaptic element. Vesicles and mitochondria are visible in the boutons, even with the dark HRP reaction product. PSDs are indicated by arrowheads. Boutons in $D$ emanated from a stalk (not illustrated in the plane of section) from the myelinated axon also seen to contain HRP reaction product. Postsynaptic targets in $D-F$ are dendritic shafts, while that shown in $G$ is a dendritic spine. Scale bar for $D-G, 1 \mu \mathrm{m}$.
} 

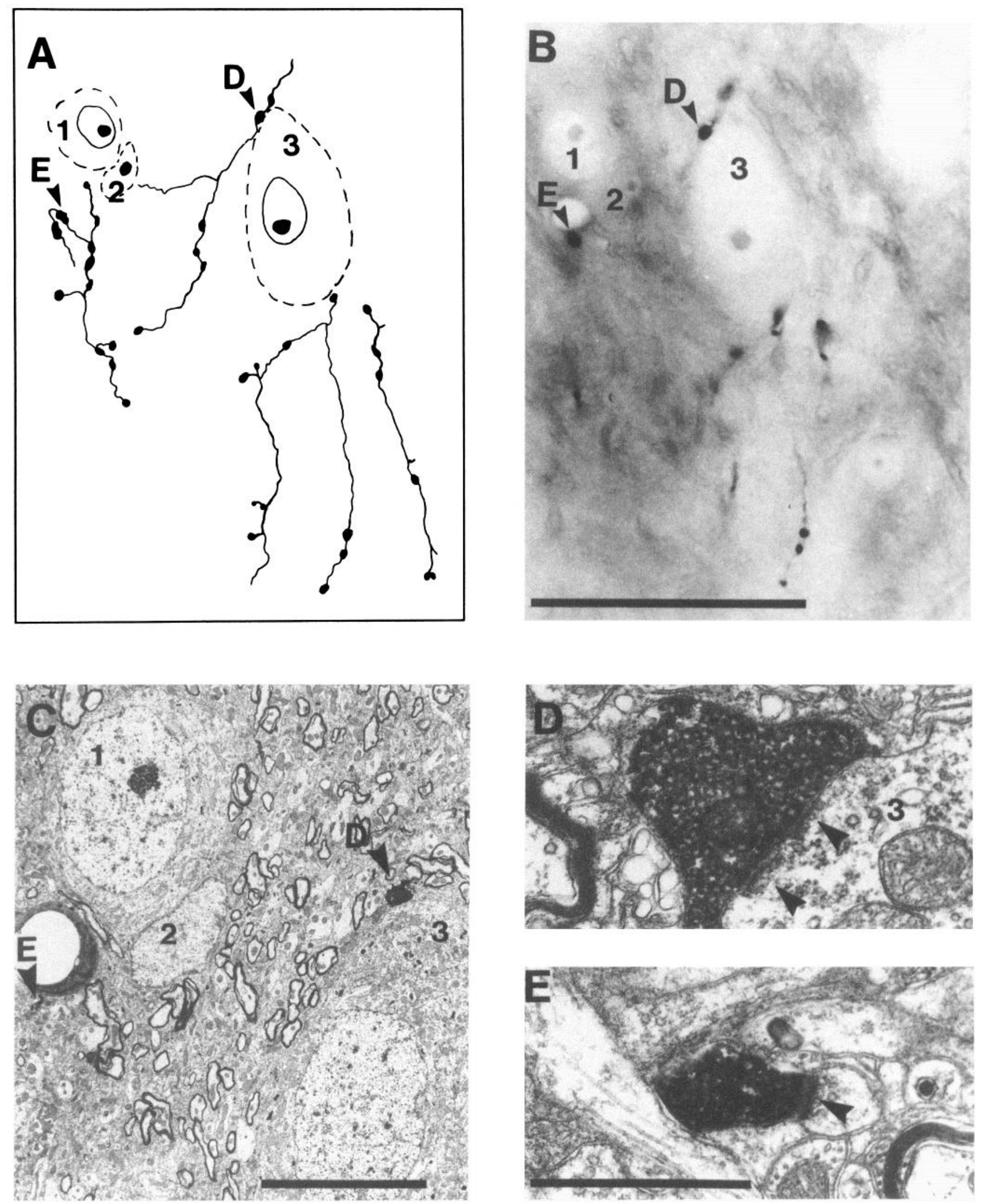

Figure 6. Correlated LM/EM analysis of boutons with sites of synaptic output for a D Y-axon in area 18. $A$ and $B$ are drawing and LM photomicrograph, respectively, of part of the axon's terminal arborization in mid-layer 4 . These panels also demonstrate that the process of osmication facilitates visualization of the cortical cells in the region of the HRP-filled terminal arborizations. Scale bar for $A$ and $B, 20 \mu \mathrm{m}$. The arrowheads and letters $D$ and $E$ indicate boutons shown in the electron micrographs illustrated in panels $D$ and $E$. Numbers $1-3$ indicate three somata used as landmarks in panel $C$. $C$, Low-magnification electron micrograph $(5000 \times$, scale bar, $5 \mu \mathrm{m})$ of field of view in panel $B$. $D$ and $E$, Higher-magnification EMs $(20,000 \times$; scale bar, $1 \mu \mathrm{m})$ of boutons $D$ and $E$. Note that bouton $D$ makes a somatic contact, while bouton $E$ contacts a spine. Arrowheads indicate PSDs. 
study of kitten and normal adult axons, the boutons were randomly selected from the central field of the terminal arborizations in layer 4 . Of the 118 boutons, 76 were fully reconstructed from serial sections ( 44 from the ND axons and 32 from the D axons). Examples of these LM/EM correlations are illustrated in Figures 5 and 6 . Figure 5 shows examples from an ND axon (the same axon illustrated in Fig. $2 B$ ). Figure 5, $A$ and $B$, shows the drawing of part of the terminal arborization and a photomicrograph through a focal plane illustrating a portion of the branches. Note the boutons corresponding to those in the drawing. Figure $5 C$ is a low-power $(5000 \times)$ electron micrograph demonstrating several of these boutons in a single section. Higher-power $(20,000 \times)$ micrographs of three of the boutons from neighboring sections are shown in Figure 5, $D-G$. Note that the synaptic targets included dendritic shafts (Fig. $5 D-F$ ) and a spine (Fig. 5G). Forty-one of 42 of the fully reconstructed boutons from the ND driven axons were found to contact at least one postsynaptic target.

An example of the correlation of boutons identified at the LM level and presynaptic profiles identified at the EM level for a $\mathrm{D}$ axon is shown in Figure 6. The drawing and light micrograph indicate the boutons of interest (Fig. $6 A, B$ ). A neuronal soma that received contacts from this arborization is illustrated. The low-power electron micrograph in Figure $6 \mathrm{C}$ shows these same boutons, and the highcr-power micrographs in Figure $6, D$ and $E$, illustrate the presynaptic profiles and their synaptic targets in more detail. An additional $\mathrm{D}$ axon bouton making a synaptic contact on a dendritic spine is illustrated in Fig. $6 E$. Of the 32 boutons from the $\mathrm{D}$ axon arbors that were fully reconstructed, 26 were observed to make synapses. Thus, as for the axonal arborizations in kittens and normal adult animals, boutons seen at the LM level are reliable indicators of the presence of synapses ( $92 \%$ of ND boutons and $80 \%$ of D boutons make synapses). Even in the few cases where a postsynaptic contact was not observed, the bouton was packed with vesicles and mitochondria, identifying it as a putative presynaptic element. (See following sections for further consideration of this point.) In all cases, the geniculocortical synapses formed by the ND and D axons are Gray's type 1 with asymmetric synaptic densities.

Quantitative analysis of arbors - $L M$. In qualitative terms, the most noticeable differences between the geniculocortical Y-axons that innervate area 18 in MD cats and similar axons in normal adult cats were in the extent of the arborizations and the density of the boutons per unit volume, in layer 4 . Specifically, the ND arbors appeared more extensive and less dense than the deprived eye axon or normal arbors. A quantitative analysis of these points is shown in Figure 7 . The same measures that were applied to the kitten and normal adult axons in an earlier study (Friedlander and Martin, 1989) were applied to the MD axons. These measures include the surface area of the boutons containing parts of the arborizations in layer 4 (Fig. $7 A$ ) and various measures of bouton density. Although three measures of bouton density were made (interbouton interval, nearest neighbor analysis, and overall bouton density), they all gave essentially the same result, and thus only the results of the overall bouton density measure are presented for the purpose of clarity (Fig. $7 B$ ).

The surface areas of the arborizations of the ND axons (Fig. $7 A$ ) were significantly larger than those of the $\mathrm{D}$ axons $(p=$ 0.002 , one-tailed Mann-Whitney $\mathrm{U}$ test) or $\mathrm{N}$ axons $(p=0.001$, one-tailed Mann-Whitney $U$ test; mean areas: $\mathrm{N}, 1.2 \times 10^{-2}$ $\left.\mathrm{cm}^{\prime} ; \mathrm{ND}, 2.6 \times 10^{-2} \mathrm{~cm}^{2} ; \mathrm{D}, 0.7 \times 10^{-2} \mathrm{~cm}^{2}\right)$. The areas of the
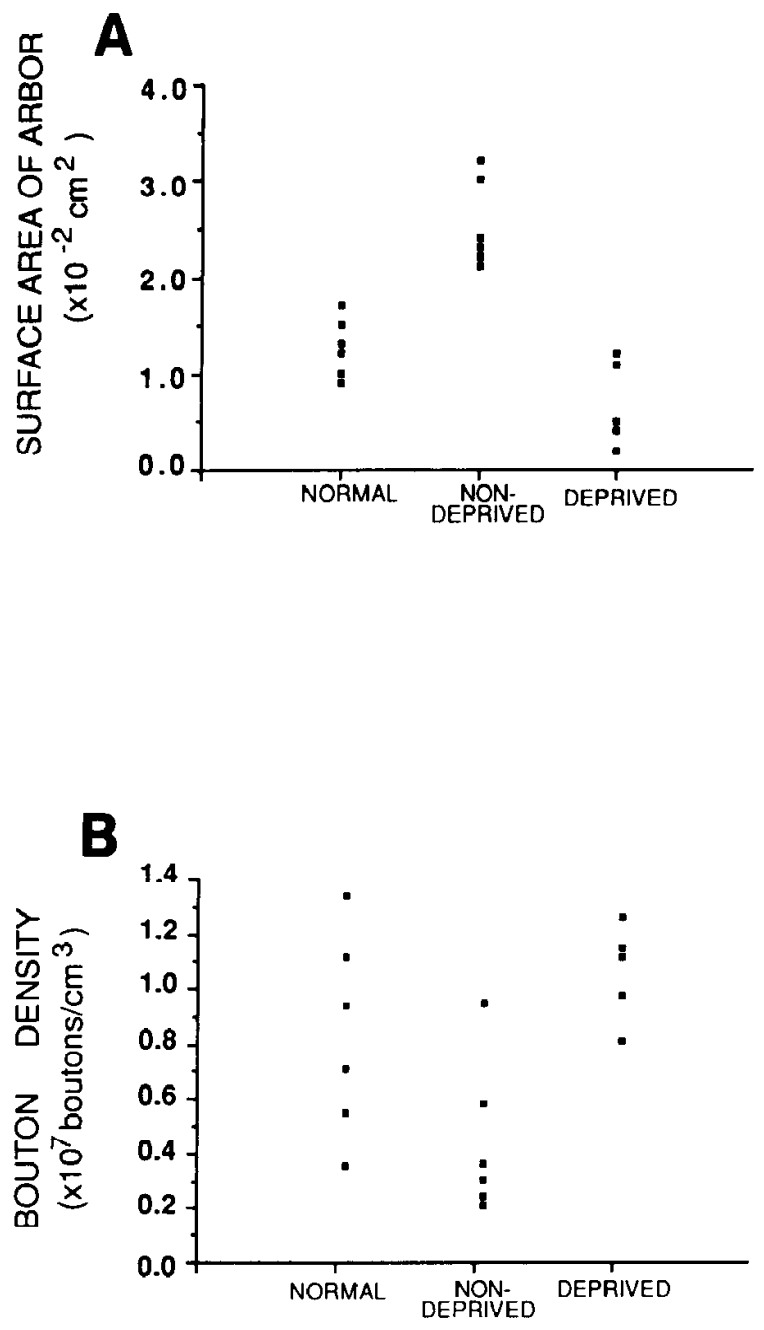

Figure 7. Summaries of distribution of boutons on axonal arborizations in layer 4 of $17\left(x_{\mathrm{N}}=6 ; x_{\mathrm{ND}}=6 ; x_{\mathrm{D}}=5\right) \mathrm{Y}$-axons that project to area 18 . Each point represents the surface area $(A)$ or bouton density $(B)$ for each arbor. The surface area measurements are for the parts of the arbors without gap between boutons, and the bouton density measurements were made for the central densest part of each axon's arborization (see Materials and Methods).

D axons were also significantly smaller $(p=0.041$, one-tailed Mann-Whitney $U$ test) than the $N$ axons but with some overlap in the samples. The bouton density (Fig. $7 B$ ) of the $\mathrm{D}$ axons was highest $\left(\right.$ mean $=1.1 \times 10^{7}$ boutons $\left./ \mathrm{cm}^{3}\right)$, while that of the $\mathrm{N}$ axons was intermediate (mean $=0.8 \times 10^{7}$ boutons $/ \mathrm{cm}^{3}$ ) and the density on the ND axons was lowest (mean $=0.4 \times 10^{7}$ boutons $/ \mathrm{cm}^{3}$ ). The $\mathrm{N}$ versus ND bouton density difference was significant ( $p=0.047$, one-tailed Mann-Whitney $U$ test), as was the ND versus D difference ( $p=0.009$, one-tailed Mann-Whitney $U$ test), but the $N$ versus $D$ groups did not differ significantly $(p=0.214$, one-tailed Mann-Whitney U test). With MD, bouton density of ND axons tended toward the lower end of the normal range, while the $\mathrm{D}$ axons tended toward the higher end of the range. The surface area and bouton density data suggest that MD results in an expansion of the ND arborizations (with concomitant reduction in bouton density) and an arrested development or contraction of the D arborizations (with concomitant increase in bouton density) with respect to the arbors of $\mathrm{N}$ adult axons. It is as if the total number of boutons on a single axon remains relatively constant and is simply distributed over a 

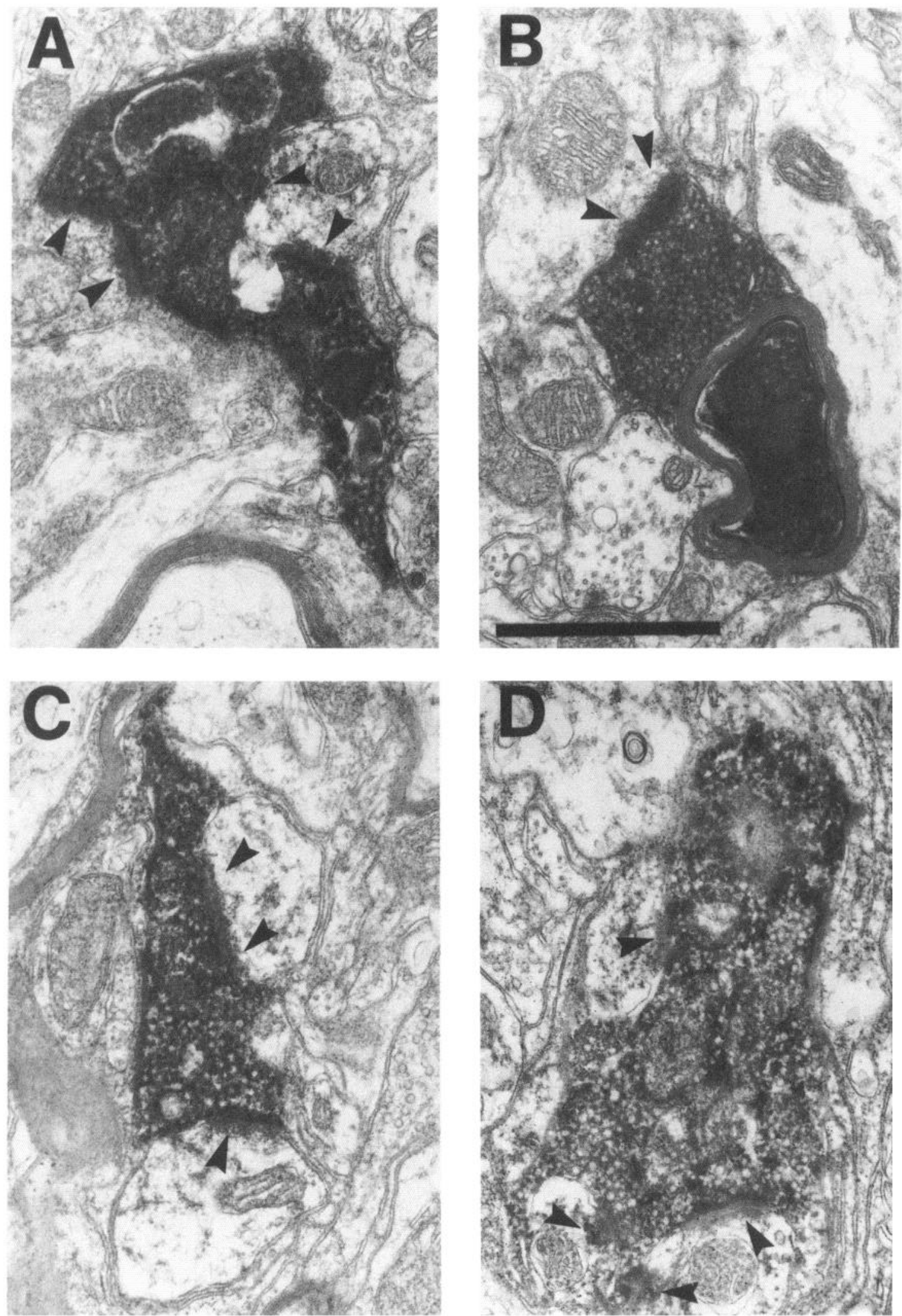

Figure 8. Example electron micrographs of individual sections from four typical layer 4 boutons from ND Y-axon arborization in area 18 of MD cats. In each case, the vesicles and mitochondria are visible in the terminals even though the density of the HRP reaction product varies considerably. Arrowheads indicate PSDs in target structures. Note that the boutons in $A, C$, and $D$ each contact several distinct targets that are visible in a single section. Also note that these boutons are typically $>2 \mu \mathrm{m}$ in length. Scale bar, $1 \mu \mathrm{m}$. 
varying volume of cortex. However, we did not make complete bouton counts for each axon (since density measures were made on the central part of the arborization), and thus we cannot be certain of the absolute bouton number.

Targets of geniculocortical axons-EM. When viewed with the electron microscope, the terminals of ND and D axons differed from each other and from their normal adult counterparts in a variety of ways. These differences included bouton size and the number of distinct postsynaptic targets contacted by each bouton. The boutons on ND axons were generally larger and made more contacts than those on D axons. Representative examples of single thin sections taken through the gcomctric center of each of four boutons from four different ND axons and $\mathrm{D}$ axons are shown in Figures 8 and 9, respectively, to illustrate this point. Note that the ND axon boutons were generally large ( $\simeq 2 \mu \mathrm{m}$ in length) and often contacted several targets. It was not difficult to obtain micrographs of single sections where an ND axon bouton made synaptic contact on two or three dendritic spines (Fig. 8A,C,D) or dendritic shaft sites (Fig. $8 B$ ). In contrast, the boutons on $\mathrm{D}$ axons were generally considerably smaller $(<1.0 \mu \mathrm{m}$ length) and usually only contacted a single site (Fig. 9A-D). Upon full serial reconstruction, the ND boutons were often seen to contact many postsynaptic targets. Typically, single thin sections through boutons from normal adult cats or kittens rarely reveal multiple contacts, and serial sections must be employed.

The types of postsynaptic target structure contacted by each bouton were determined by the various ultrastructural criteria routinely used to discriminate dendritic spines, dendritic shafts, and somata (see Materials and Methods). In many cases, sequences of serial sections were necessary to verify a postsynaptic structure's identity since a single section may not definitively reveal the subcellular organelles typically associated with the structure. Thus, for identification of the postsynaptic structure, we used only our data from full serial reconstructions of the boutons, which included sufficient reconstruction of the target structure to confirm its identity. These data are summarized in Figure 10. The data for the boutons from each axon are presented in Figure 10, $A-C$, and the pooled data for the boutons from all axons in each group are illustrated in $D-F$. The distribution of synaptic targets for geniculocortical $\mathrm{Y}$-axons that project to area 18 in normal adult cats favored dendritic spines ( $70 \%$ of targets; range $=65-75 \%)$ versus dendritic shafts $(20 \%$ of targets; range $=16-22 \%)$ or somata $(10 \%$ of targets; range $=$ 7-14\%). The distribution was shifted in MD cats, particularly for the synapses formed by boutons of ND axons, which increased relatively their innervation of dendritic shafts. The resulting distribution of targets for ND axons was as follows: dendritic spines, $55 \%$ (range $=36-73 \%$ ); dendritic shafts, $40 \%$ (range $=22-60 \%$ ); somata, $3 \%$ (range $=0-5 \%$ ). This difference in overall distribution between N and ND boutons was significant if each bouton was treated as an independent observation (N vs. ND, $p=0.0001, \chi^{2}$ test) or when each axon was treated as an independent observation (e.g., $\mathrm{N}$ vs. ND proportion of dendritic shaft synapses, $p=0.028$, one-tailed Mann-Whitney $\mathrm{U}$ test). Similarly, the difference in the overall distribution of targets was significant for ND versus D boutons $(p=0.0001$, $\chi^{2}$ test), as was the difference when each axon was treated independently (ND vs. D proportion of dendritic shaft synapses, $p=0.016$, one-tailed Mann-Whilney $\mathrm{U}$ test). There were no significant differences in the synaptic target distribution for boutons of $N$ versus $\mathrm{D}$ axons $\left(p>0.1, \chi^{2}\right.$ test for overall distribution; $p>0.05$, one-tailed Mann-Whitney $\mathrm{U}$ test for proportion of dendritic shaft synapses for individual axons).

Quantitative analysis of geniculocortical terminals-EM. In order to assess adequately certain structural parameters of the boutons and their postsynaptic targets, it was necessary to use full three-dimensional reconstructions from complete series of sections through the entire bouton. This method was used for analysis of the number of anatomically distinct targets per bouton, bouton volume, number and volume of mitochondria per bouton, and area of PSD contacted by each bouton. Examples of these data and the analytical methods applied are illustrated in Figure 11. The results of these analyses are shown in Figures 12-15.

The digitized and reconstructed image of a full series of 52 sections of a reconstructed ND bouton and the associated structures including mitochondria, postsynaptic target structures, and PSD is shown in Figure 11A. For comparison, reconstructions of another bouton from an ND axon and two boutons from D axons are shown in Figure 11, $B-D$, respectively. These reconstructions are representative of the sample of boutons from ND and $\mathrm{D}$ axons and illustrate several points that are substantiated by the quantitative comparisons made in the following figures. The boutons of ND axons typically were larger in volume, contained more mitochondria, and contacted multiple distinct postsynaptic targets compared to the boutons of D axons, which occupied less volume, had fewer mitochondria, and contacted fewer (usually only one) distinct postsynaptic targets.

The distributions of volumes for all boutons from ND versus $\mathrm{D}$ axons are plotted in the histograms in Figure 12, $A$ and $B$, respectively. The ND boutons were significantly larger than the $D$ boutons (ND mean $=3.4 \pm 0.5 \mu \mathrm{m}^{3}, \pm \mathrm{SEM} ; \mathrm{D}$ mean $=1.2$ $\pm 0.1 \mu \mathrm{m}^{3}, \pm \mathrm{SEM} ; p<0.005, \chi^{2}$ test). A major difference in the distributions was the proportion of very large $\left(>3.0 \mu \mathrm{m}^{3}\right.$, $>40 \%$ ) ND boutons versus D boutons $(<5 \%)$. The volume difference was also significant when each individual axon's boutons are compared individually (Fig. 12C; $p<0.001$, one-tailed Mann-Whitney U test).

The distributions of the numerical output to postsynaptic targets for all of the boutons are shown in Figure 13. For Y-axons that project to area 18 in normal animals, the most frequently observed number of contacts was two per bouton (Fig. 13A). However, in MDs this was not the case for boutons from ND or D axons (Fig. 13B,C, respectively). For ND axons (Fig. 13B), the distribution was wider, with $>30 \%$ of the boutons contacting from three to eight postsynaptic targets. The number of synaptic targets contacted by the ND boutons was signifcantly greater than that for the D boutons (ND mean $=1.8 \pm$ $0.2, \pm$ SEM, synapses per bouton; $\mathrm{D}$ mean $=1.3 \pm 0.1, \pm \mathrm{SEM}$; $p<0.005, \chi^{2}$ test). Moreover, even though the mean number of contacts for ND and normal boutons was the same (1.8), the distributions were significantly different $\left(p<0.005, \chi^{2}\right.$ test $)$. The individual ND boutons had a wider range in their number of synaptic contacts with $15 \%$ innervating from 4 to 12 targets. The D axons (Fig. 13C) also differed in their number of synapses per bouton as compared to control axons from normal animals $(\mathrm{D}$ mean $=1.3 \pm 0.1, \pm \mathrm{SEM} ; \mathrm{N}$ mean $=1.8 \pm 0.2, \pm \mathrm{SEM} ; p$ $<0.005, \chi^{2}$ test). These differences in the numbers of synapses for the sample of boutons on each individual axon are summarized in Figure 14. Analysis of these data showed that the difference between the $\mathrm{N}$ axons and $\mathrm{D}$ axons and the difference between the ND axons and D axons were significant ( $p=0.018$ and $p=0.008$, respectively, one-tailed Mann-Whitney U tests), 

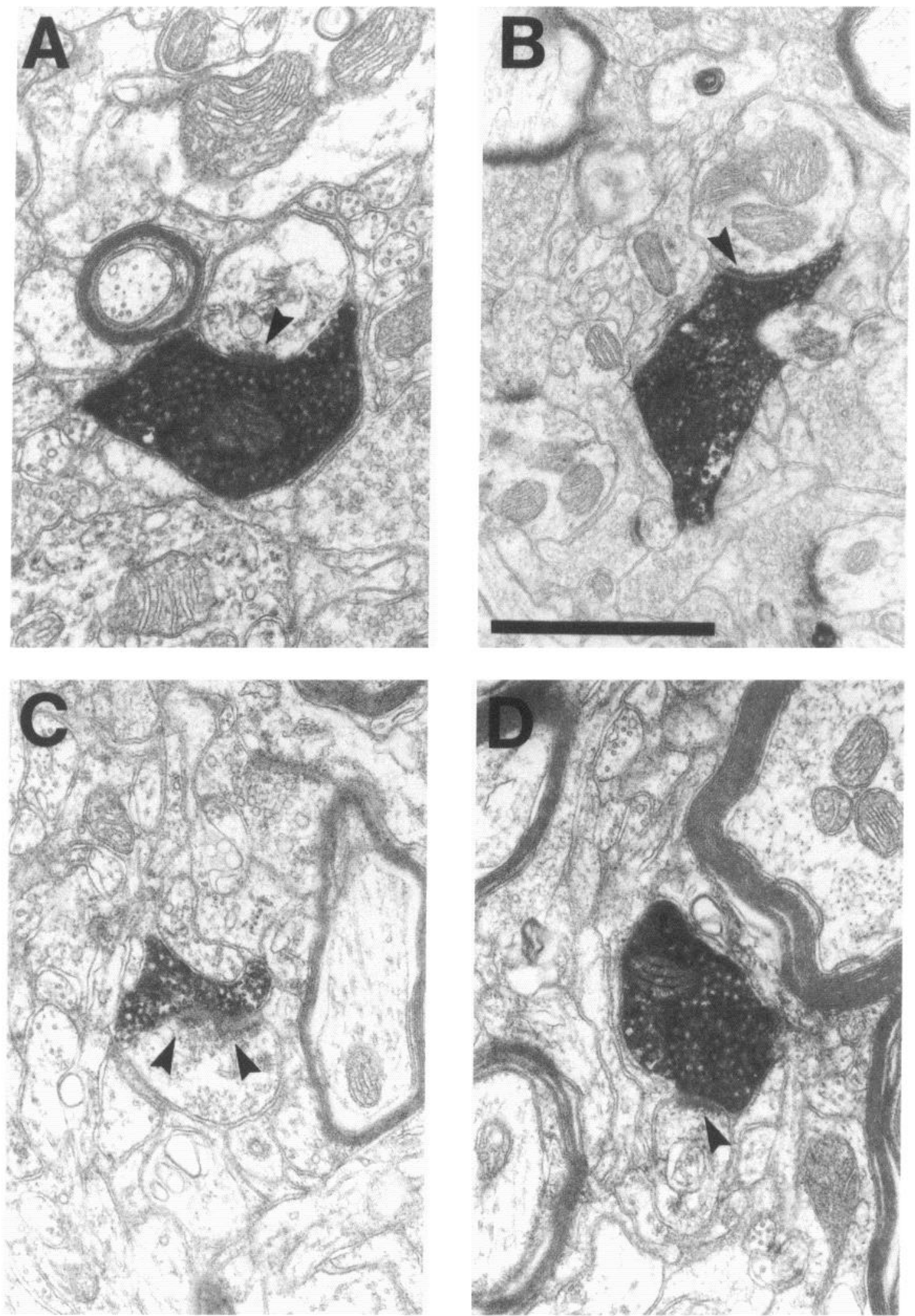

Figure 9. Example of electron micrograph of individual sections from four typical layer 4 boutons from D Y-axon arborizations in area 18 of MD cats. Note the small size of the boutons (generally $<1 \mu \mathrm{m}$ in length) and the simple single contacts, generally on dendritic spines (arrowheads indicate PSDs on synaptic targets). Scale bar, $1 \mu \mathrm{m}$. 

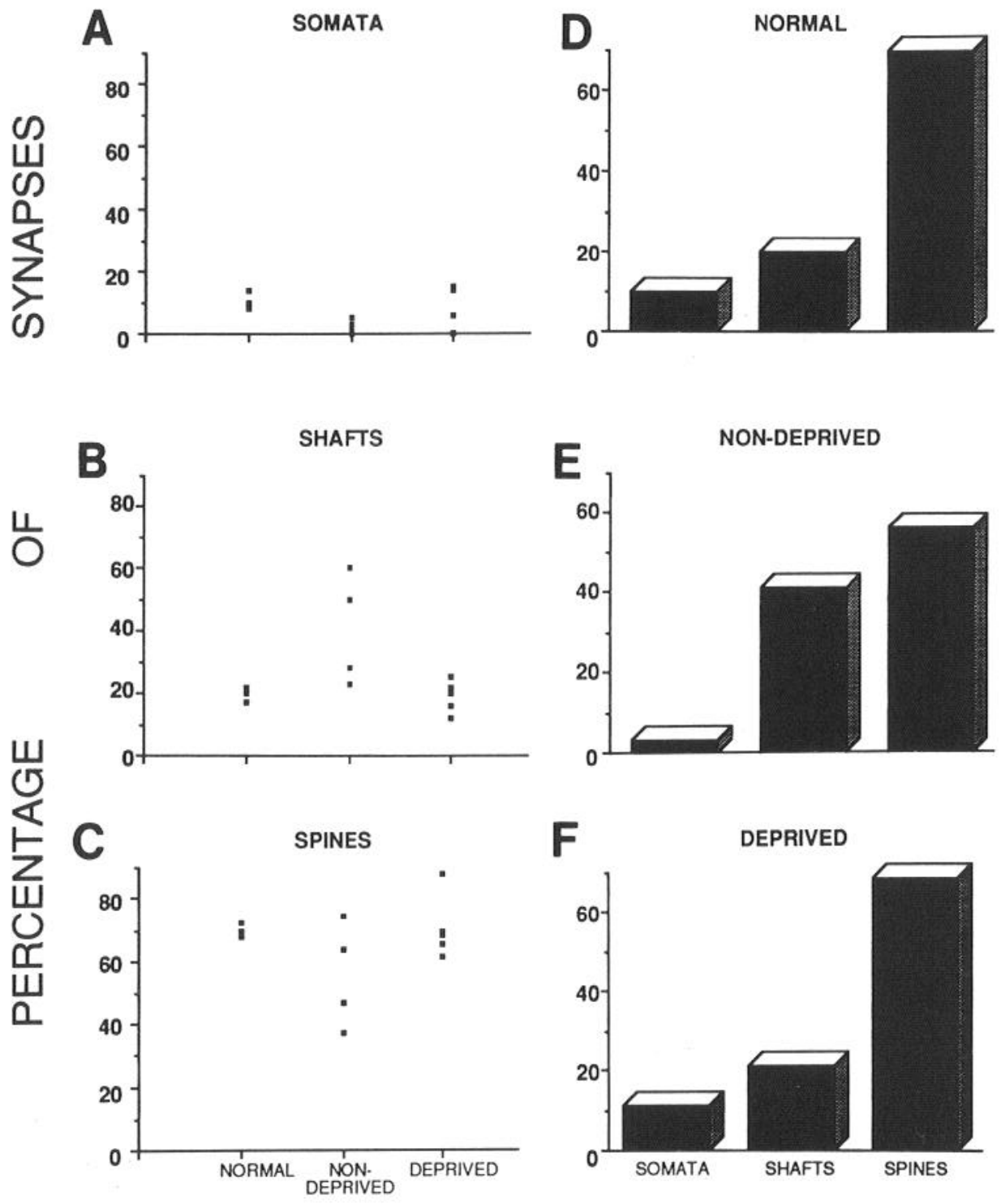

Figure 10. Distribution of types of synaptic targets (somata, dendritic shafts, or dendritic spines) in layer 4 for boutons from N, ND, and D area 18projecting $\mathrm{Y}$-axons in normal and $\mathrm{MD}$ cats. Left column $(A-C)$ illustrates mean value (percentage of all synapses found by all boutons studied for each axon) of the percentage of synapses formed on the various target types. Each point is the mean for an individual axon for a sample of 30-74 synapses formed by 23-42 boutons studied for each axon. Right column $(D-F)$ shows distribution of synaptic targets for all synapses when all 600 synapses from 372 boutons were analyzed by pooling data from all axons in each group (N, ND, and $\mathrm{D}$ ) and treating each bouton as an independent observation. The only significant change in the distributions is for the boutons from ND axons that make a greater fraction of synapses on dendritic shafts than either the $\mathrm{N}$ or D axons.

but the difference between the N and ND axons was not significant ( $p=0.057$, one-tailed Mann-Whitney U test).

The number of mitochondria in the total samples of boutons differed for the ND and D group in the MD animals (Fig. 15A, $B$; $\mathrm{ND}$ mean $=5.3 \pm 0.6, \pm \mathrm{SEM} ; \mathrm{D}$ mean $=2.6 \pm 0.3, \pm \mathrm{SEM}$; $p<0.01, \chi^{2}$ test). Note that $>30 \%$ of the ND boutons had more than eight mitochondria per bouton (ranging up to 20 mitochondria in several cases), while only $1 \%$ of the D boutons had more than eight mitochondria. This significant difference was also found for the individual axons (Fig. $15 C ; p=0.016$, twotailed Mann-Whitney U test). It was of interest to determine whether the boutons on ND axons were qualitatively different in their capacity to pack mitochondria into a given volume of presynaptic element or if the bouton number simply reflected the larger bouton sizes. The relationships of bouton volume to number of mitochondria per bouton (not illustrated) for the ND and $\mathrm{D}$ samples were fit by the same linear relation: $y=0.52 x$ $+0.18 ; r=0.85$. Thus, the greater number of mitochondria in ND boutons was not more than would be expected on the basis of their increased size alone.

The areas of the PSDs were derived from reconstructions of full sets of serial sections (not illustrated). In cases of perforated
PSDs, they were counted as a single density, and the total area, not including perforations, was measured. Sufficiently large samples of reconstructions of PSD area were obtained for synapses on dendritic shafts and spines from ND and D axons, but not for somata, which generally accounted for less than $10 \%$ of the synapses found (Fig. 10). The only significant difference for PSD area comparisons was between the ND and D groups for dendritic shaft synapses $\left(\mathrm{ND}\right.$ mean $=0.19 \pm 0.02 \mu \mathrm{m}^{2}, \pm \mathrm{SEM}$; D mean $=0.13 \pm 0.02 \mu \mathrm{m}^{2}, \pm \mathrm{SEM} ; p<0.01, \chi^{2}$ test $p<0.04$, two-tailed Mann-Whitney U test). The PSD areas for dendritic spines did not differ $\left(\right.$ ND mean $=0.13 \pm 0.01 \mu \mathrm{m}^{2}, \pm \mathrm{SEM} ; \mathrm{D}$ mean $=0.16 \pm 0.01 \mu \mathrm{m}^{2}, \pm \mathrm{SEM} ; p>0.05, \chi^{2}$ test; $p>0.05$, two-tailed Mann-Whitney U test). The areas of PSDs on dendritic shafts were larger than on spines for both the ND and D axons.

\section{Discussion}

\section{Summary of findings}

There are four major findings from our study (summarized diagrammatically in Fig. 16) of the effects of long-term MD on the innervation of cortical area 18 in the cat by individual geniculocortical Y-axons. (1) Despite long-term deprivation, result- 


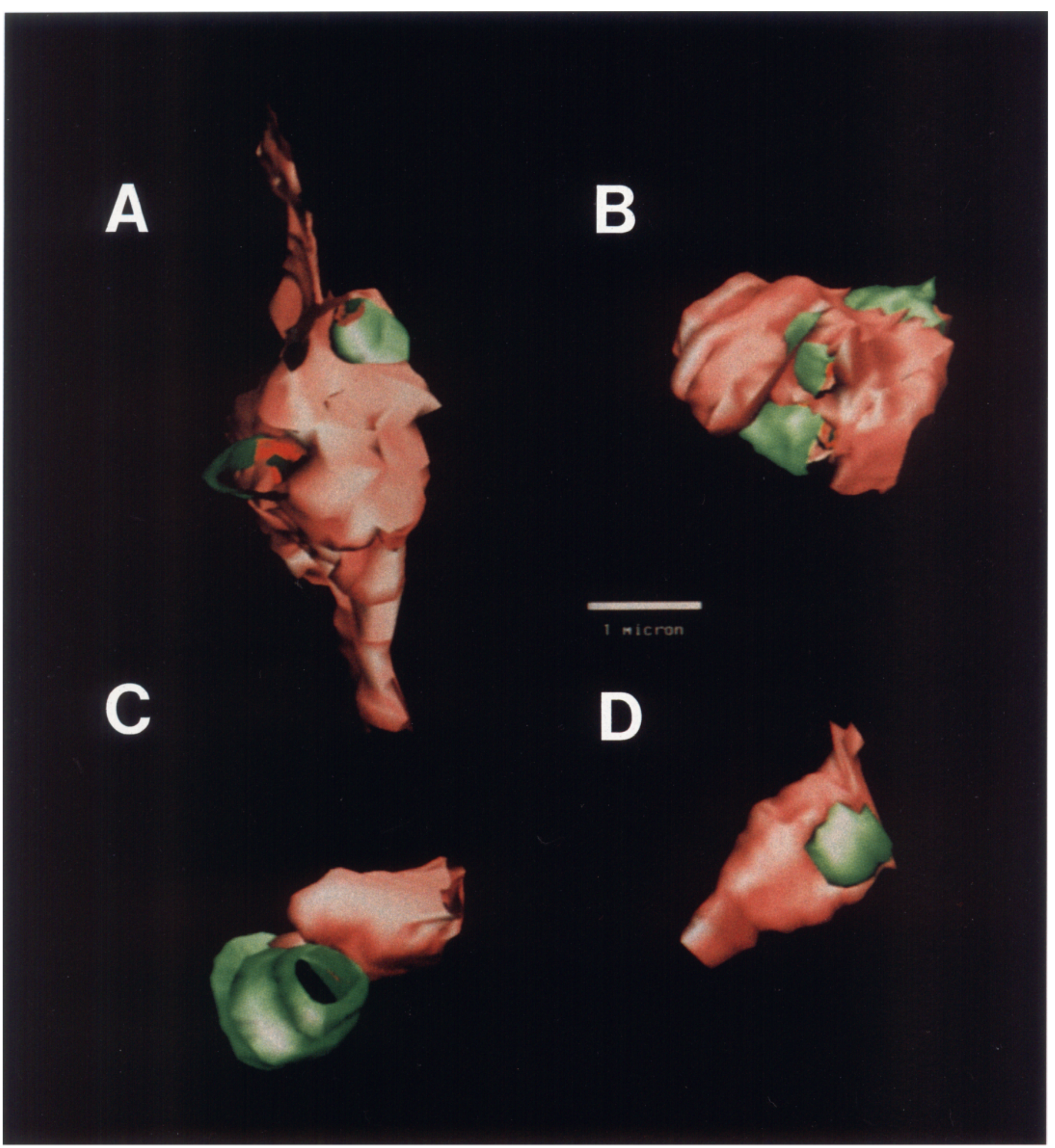

Figure 11. Reconstructed solid images of four typical boutons (pink) and their postsynaptic targets (green) generated from digitization, section alignment, and subsequent areal and volume measurements. PSDs are indicated in orange. $A$ and $B$ are boutons of ND Y-axons in layer 4 of area 18 from MD cats. The reconstruction in $A$ is of the same ND bouton illustrated in the electron micrographs in Figure 8 . $C$ and $D$ are reconstructions of boutons of $\mathrm{D}$ axons in layer 4 of area 18 in MD cats. Note the larger ND boutons with more contacts. Scale bar, $1 \mu \mathrm{m}$.

ing in virtually complete functional dominance of the nondeprived eye over cortical neurons, geniculocortical axons driven via the deprived eye continue to maintain rich, albeit reduced, terminal arborizations in the cortex. (2) Although the D arbors from MD cats are smaller than those from normally reared animals, they support a higher bouton density. The ND arbors are larger than those from normal animals but have a lower bouton density. (3) ND boutons are larger and make more syn- 

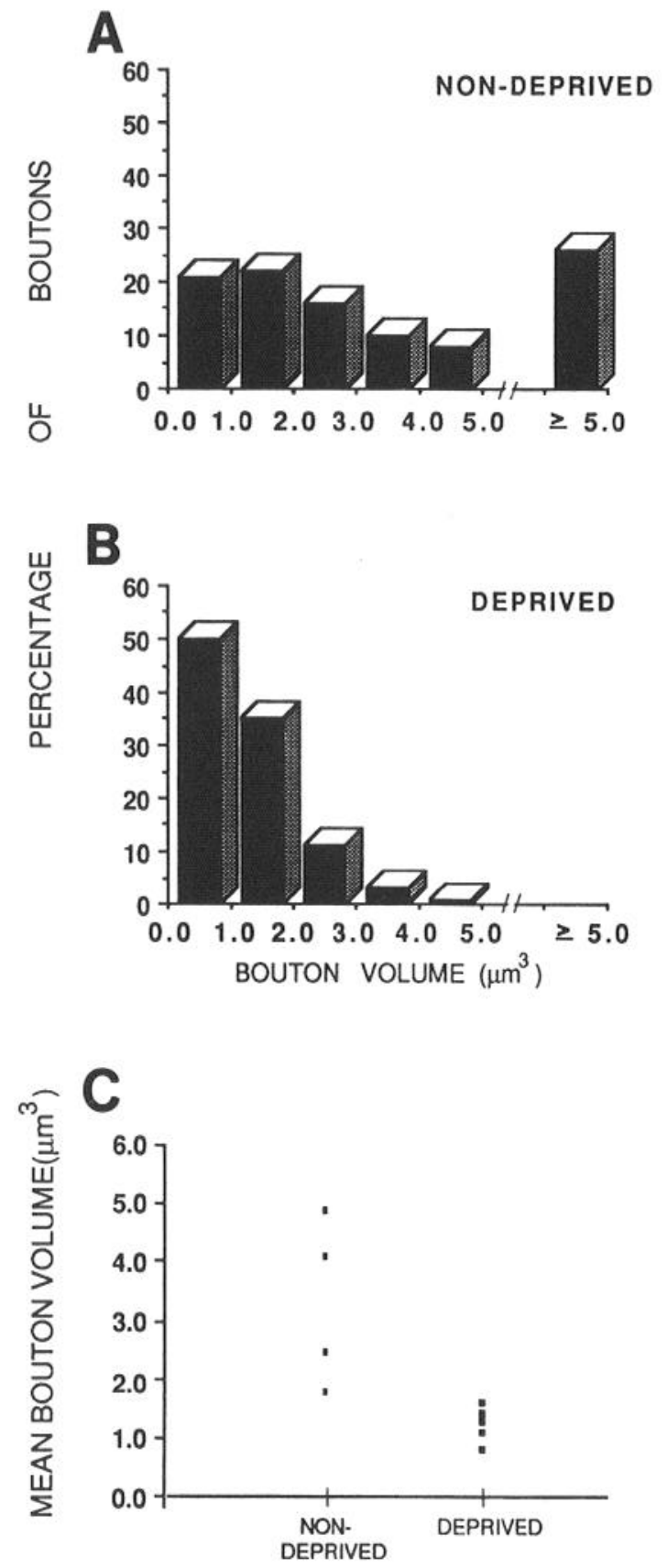

Figure 12. Summary of analysis of bouton volume for layer 4 boutons on $\mathrm{Y}$-axons in area 18 of MD cats. Volume data were obtained from serial reconstructions. $A$ and $B$, Histograms illustrating the distribution of volumes for all of the boutons (ND boutons, $n=129$; D boutons, $n$ $=139$ ). $C$, Plot of mean values for bouton volume for each of four ND and five D axons (from 23-42 boutons analyzed per axon).

apses per bouton on average than those from normal animals, whereas D boutons are smaller and make fewer synapses per bouton. (4) ND boutons have more mitochondria and make proportionally more, and larger, synapses on dendritic shafts than D boutons, which synapse on the same proportions of dendritic shafts, spines, and somata as $\mathrm{N}$ axons.

\section{Effects of sampling}

It has been apparent over the course of this and our previous study (Friedlander and Martin, 1989) that our micropipettes
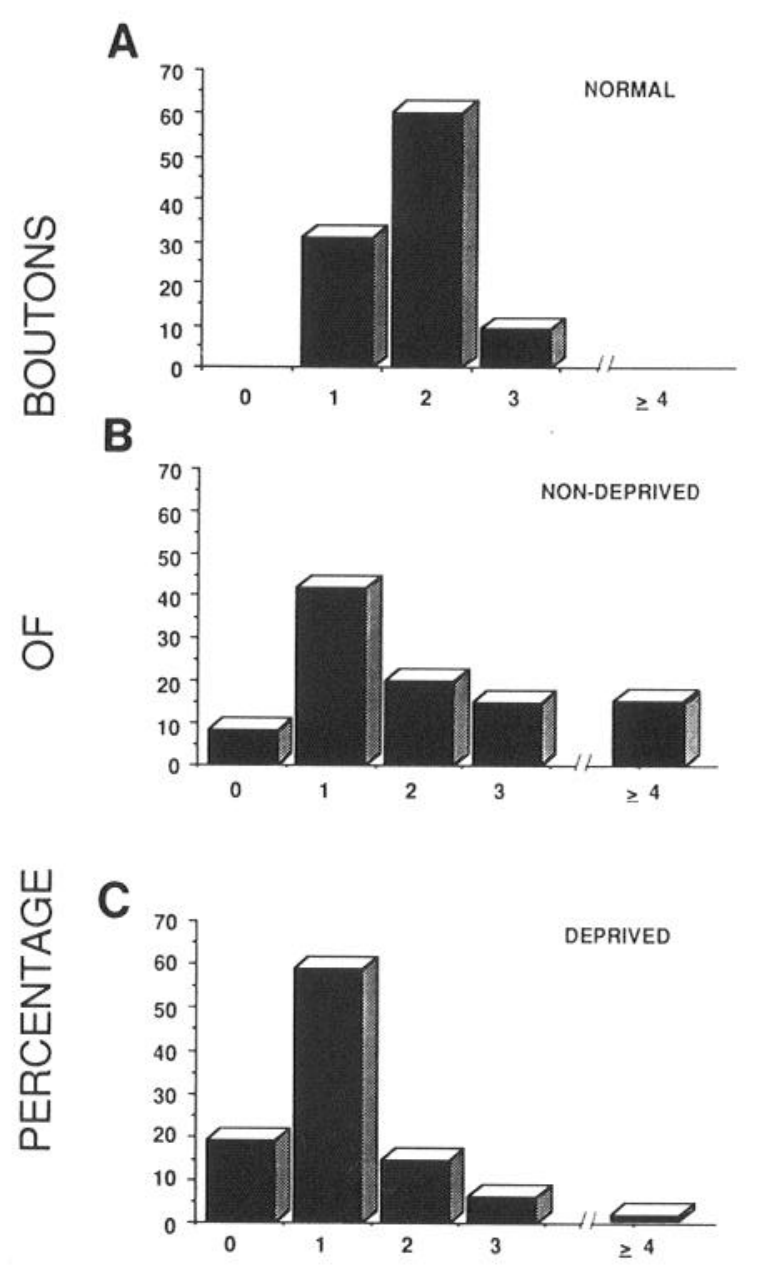

\section{NUMBER OF POSTSYNAPTIC TARGETS}

Figure 13. Distribution of the number of distinct postsynaptic targets that received synaptic input from individual boutons for axons in normal animals and ND and D Y-axons in layer 4 of area 18 in MD cats.

favor obtaining intracellular recordings from larger axons [3:2 $\mathrm{Y}$ - to $\mathrm{X}$-axon recordings, while the actual $\mathrm{Y}$ :X-cell ratio in the LGN is closer to 1:2 (Friedlander et al., 1981)]. Thus, any factors that significantly affect the size of the axons, such as MD might, could conceivably bias the sample obtained. For example, if MD caused more profound physiological (Friedlander et al., 1982) effects on Y-axons from the deprived eye and a greater shrinkage of these axons' diameters and arbor sizes, our sample could underestimate the severity of the structural changes caused by MD. Thus, the profound structural changes that we observed, particularly at the ultrastructural level, may be a conservative estimate if such severely affected axons were excluded from our sample. It should also be emphasized that our analysis of the structural changes in the $\mathrm{Y}$-geniculocortical innervation of area 18 reflects only the functional $\mathrm{Y}$-cell input that actually gets to this area of cortex. We previously found (Friedlander et al., 1982) that MD causes some $\mathrm{LGN}_{\mathrm{d}}$ cells with Y-type dendritic morphology to be dominated by X-type functional retinal input. Of course, since such a cell's axon would be functionally identified as an X-axon while recording from the cortical white matter, it would not be included in the present structural analysis. Thus, added to the structural alterations that we have ob- 


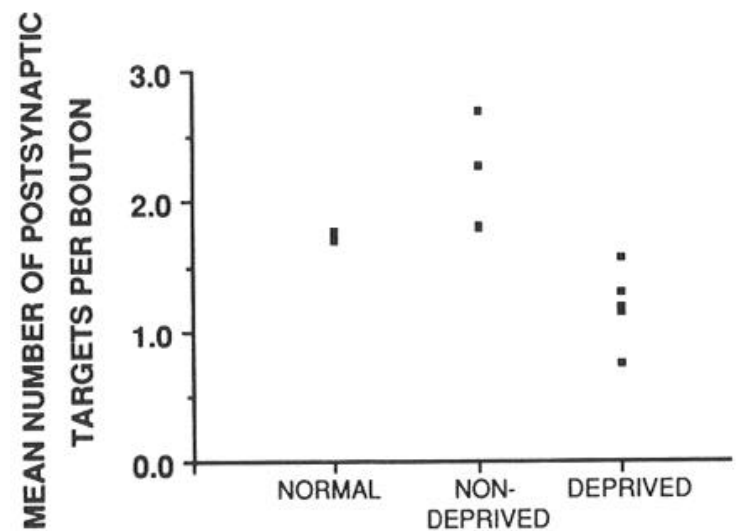

Figure 14. Summary of mean number of postsynaptic targets innervated by sample of boutons for each axon.

served could possibly be additional changes in geniculocortical synapses routed to cortex by morphological Y-type cells. However, from a functional point of view, our data compare only the distribution and synaptic structure of physiological Y-type signals that reach cortical area 18 .

\section{Possible mechanisms that underlie MD effects in cortex}

It is well established that MD results in a profound shift in the functional ocular dominance of cortical neurons. Five possible mechanisms (not necessarily mutually exclusive) may underlie this shift. (1) The individual geniculocortical axon arborizations (and possibly the corticocortical axon arborizations within a column) change size-ND arbors expand and D arbors shrink. (2) The degree of overlap of axonal arborizations within a column changes, producing smaller D columns and larger ND columns (with no change in the size of individual arborizations). (3) The distribution of the axonal arborizations remains unchanged, but the synapses formed by the axons have diminished functional capacity. (4) The macroscopic distribution of the axonal arborizations remains unchanged, but the arrangement of the synapses onto target cells is altered. (5) The distribution of axonal arborizations remains unchanged, but their outputs are functionally suppressed. While our results do not conclusively discriminate among all of these possible mechanisms, they do shed light on the likelihood of several of these alternatives. The evidence is considered in the following sections.

\section{Relationship of ocular dominance columns to individual geniculocortical axonal arborizations}

The clearest view of the mechanisms underlying the development and plasticity of ocular dominance columns has been given by the combined electrophysiological and anatomical work of Hubel and Wiesel and their collaborators (Wiesel and Hubel, 1963, 1965; Hubel et al., 1977; Shatz and Stryker, 1978; LeVay et al., 1980). In their studies on area 17, a correlation was found between the extent of the geniculocortical afferent distribution in layer 4 and the ocular dominance distribution obtained from single-unit recordings. The most parsimonious interpretation is that ocular dominance assessed physiologically is a direct outcome of the underlying distribution of geniculocortical afferents of the two eyes. In cases of MD, the increased size of the ND columns is thought to reflect expansion of individual ND geniculocortical axonal arborizations, while reduced size of D columns reflects contraction (or failed developmental expansion) of in-
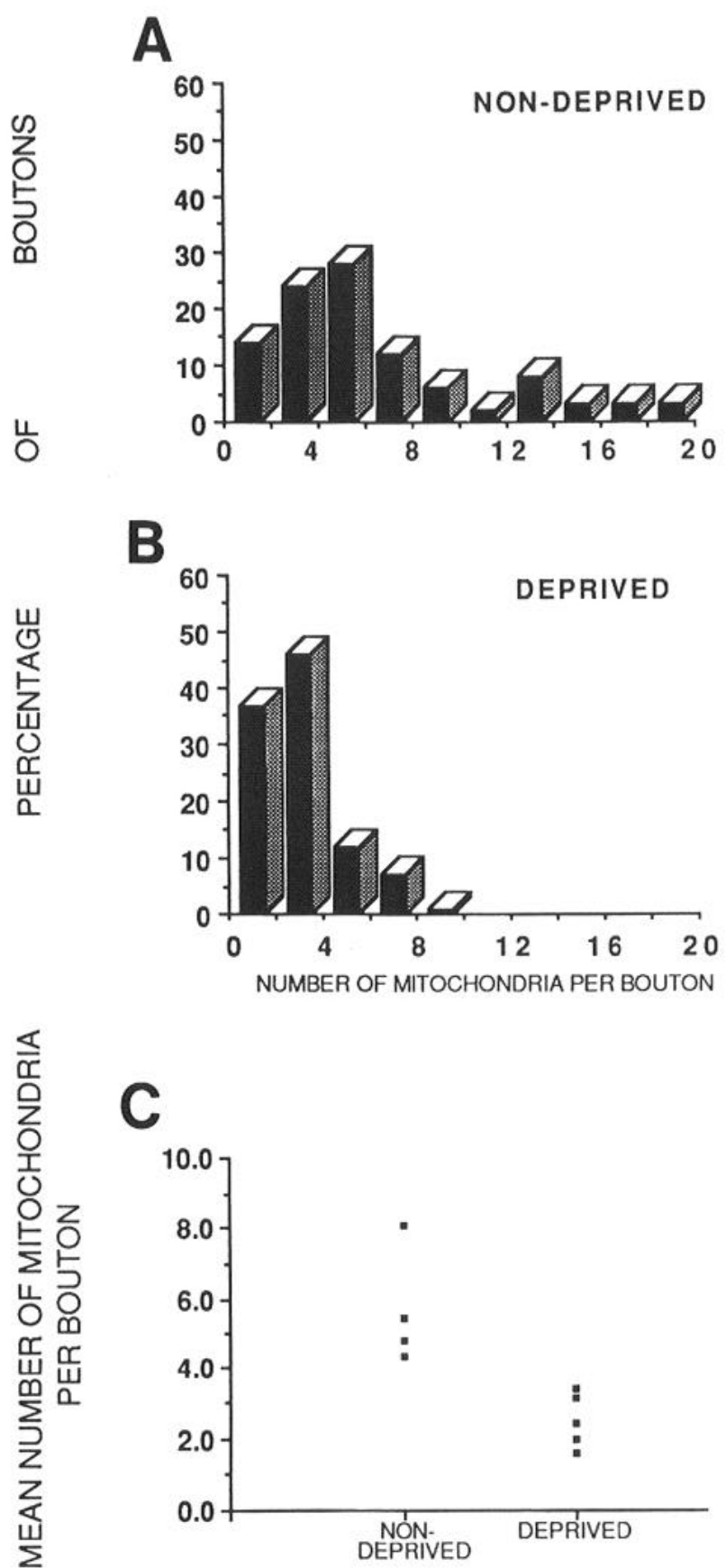

Figure 15. Distribution of the number of mitochondria contained within each bouton. $A$ and $B$, Frequency distribution histograms of number of mitochondria for all boutons for the entire sample of boutons studied for ND and D axons. $C$, Comparison of mean number of mitochondria per bouton for each ND and D axon.

dividual D geniculocortical axon arborizations. Our results from area 18 of MD cats demonstrate that such a direct link cannot be made between the change in the size of individual geniculocortical axon arborizations (present results) and the functional change in ocular dominance in this area (Singer, 1978; Mitzdorf and Singer, 1980). The extent of the deprived arborizations was larger than would be predicted from the physiological ocular dominance distribution. The greater shrinkage of entire ocular dominance columns observed anatomically in areas 17 and 18 has been assessed by the pattern of labeling that results from 


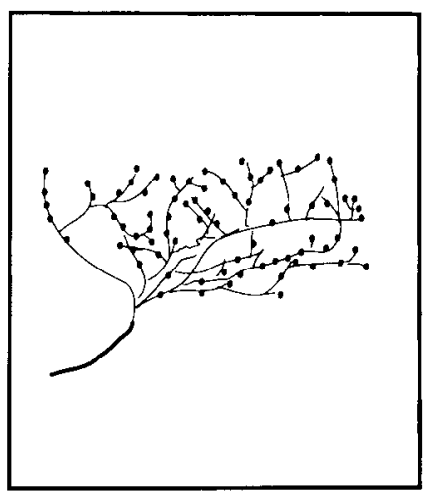

NORMAL ADULT

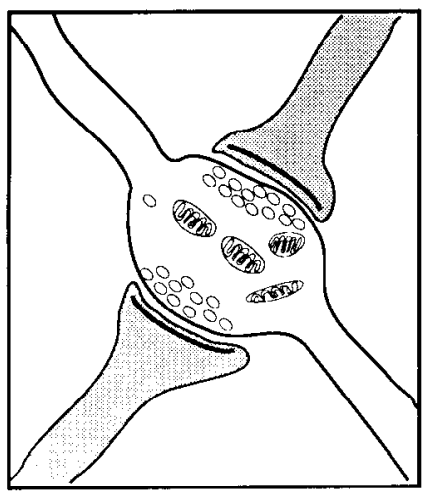

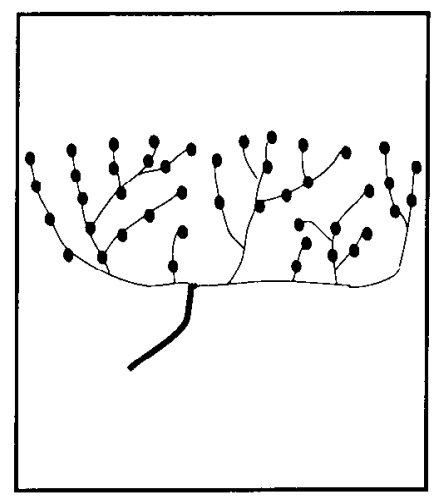

MD - ND

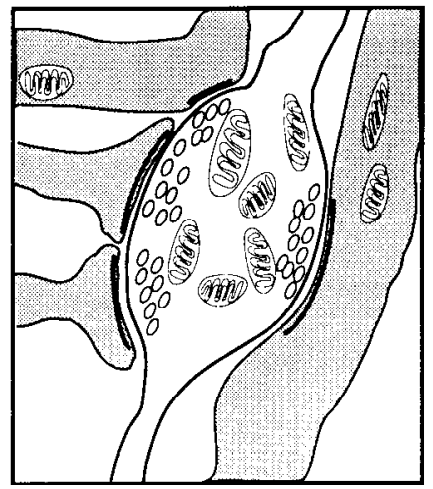

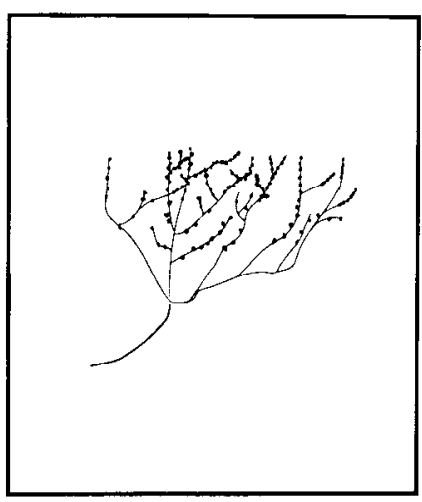

MD - D

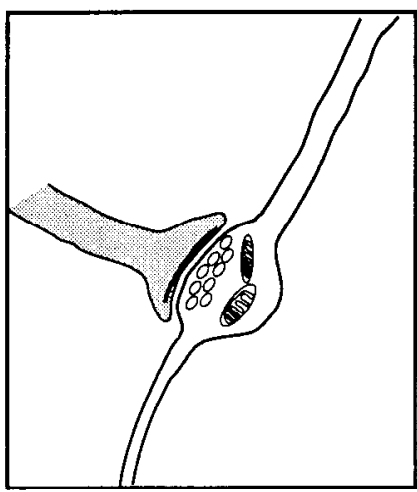

Figure 16. Summary diagram illustrating major significant differences in axon arborizations and ultrastructure of individual synapses for $\mathrm{Y}$-axon geniculocortical contacts in layer 4 of area 18 in normal and MD cats. MD causes arborizations of individual $\mathrm{Y}$-axons to change in their extent and the density of boutons. ND axons cover a larger extent (medio-lateral $\times$ rostrocaudal) and space their boutons more widely. The D axons' extent of cortical coverage is rcduced, and their density of boutons is higher (with the centermost part of their arborizations). They also contain more isolated peripheral branches with sparse bouton coverage. The individual boutons of ND axons are larger than those of D axons. (Boutons of $Y$-axons in area 18 of normal cats are intermediate in size as determined by a large sample of bouton sizes measured for over 3000 boutons at the LM level but not illustrated in the study.) The boutons of ND axons vary considerably in the number of targets contacted but in many cases contact multiple targets (4-12). These targets include a greater proportion of dendritic shafts than for axons from normal animals or $\mathrm{D}$ axon boutons in MD animals. The ND boutons contain more mitochondria and innervate zones with larger PSDs on dendritic shafts. The $\mathrm{D}$ boutons are generally smaller, contact fewer targets, prefer spines as do normal axons, have fewer mitochondria, and often do not form any synapses. the transsynaptic transport of radiolabeled tracers injected into one eye (Shatz and Stryker, 1978). However, our results on the structural changes of geniculocortical boutons suggest that other factors contribute to the pattern of column labeling; for example, the boutons of the ND arbors were significantly larger and more mitochondria-rich than those of D arbors. The large ND boutons might accumulate more tracer and so would dominate the picture, while the $\mathrm{D}$ boutons, being significantly smaller, would be less visible except where they were clustered particularly densely. Thus, the transsynaptic method may exaggerate the apparent shift in distribution of the D and ND afferents. Alternatively, the structural changes that we observed for $\mathrm{Y}$-geniculocortical axons in MD area 18 may differ from those that occur for other functional types of axons in other cortical areas (such as $\mathrm{X}$ - and lagged $\mathrm{X}$-cell axons that project to area 17). However, our preliminary data (Friedlander et al., 1990) on the development of $\mathrm{X}$ - and $\mathrm{Y}$-axons that innervate area 17 suggest that at least the normal developmental mechanisms are similar.

While our data clearly demonstrate that the extent of individual geniculocortical axon's arborizations changes with MD, other mechanisms should also be considered to explain the physiological effects. Changes in the extent of intracortical axonal arborizations should be evaluated by intracellular labeling of cortical cells in MD cortex with concomitant labeling of ocular dominance of columns. Likewise, evaluation of the effects of MD on the degree of overlap of axonal arborizations within a column requires intracellular labeling of geniculocortical axons or cortical cells in MD cortex in which ocular dominance columns have been labeled.

\section{Relationship of structural changes in geniculocortical synapses to $M D$}

The structure of geniculocortical synapses is profoundly affected by MD. These effects include reduced bouton size and number of mitochondria, fewer synaptic targets and smaller dendritic shaft synapses for the D axons, and larger boutons with more mitochondria, more postsynaptic targets, and increased size and proportion of dendritic shaft contacts for the ND axons. These morphological changes may alter the balance in eflicacy of synaptic transmission at these sites. Although few cortical neurons with suprathreshold responses to visual stimulation through the deprived eye are found with extracellular recording in areas 17 (Wiesel and Hubel, 1963) or 18 (Singer, 1978; present results), subthreshold input is revealed by intracellular recording of synaptic responses in area 17 in response to electrical stimulation of the deprived eye's optic nerve afferents (Tsumoto and Suda, 1978). This experiment reveals latent deprived eye inputs in area $17 \mathrm{MD}$ cortex. In support of the hypothesis that there arc persistent connections from the deprived eye are experiments

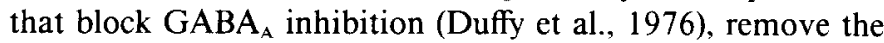
nondeprived eye (Kratz et al., 1976), and provide appropriate phase relationships of combined binocular visual stimuli to both eyes (Freeman and Ohzawa, 1988). It is not known whether such latent inputs can be revealed in area 18 of MD cats. If so, the smaller boutons and PSDs on dendritic shafts may contribute to these weakened responses by limiting neurotransmitter release or the size of the receptor surface, respectively. The profound reduction in visual responsiveness of cortical neurons 
to stimulation through the deprived eye as evaluated by extracellular recording of action potentials may reflect a reduced capacity for the $\mathrm{D}$ axon boutons to sustain transmitter release during high-frequency impulse trains. Such fatigue as well as longer response latencies are characteristic of neocortical neurons in immature (Hubel and Wiesel, 1963; Purpura et al., 1965; Kato et al., 1983) or visually deprived animals when the deprived eye is activated (Shatz and Stryker, 1978). Interestingly, the ultrastructure of the immature geniculocortical synapses in the $\mathrm{Y}$-cell pathway resembles the $\mathrm{D}$ axon synapses (Friedlander and Martin, 1989; see also below). Moreover, synergistic interactions such as paired-pulse facilitation during high-frequency discharge of a presynaptic element are generally attributed to presynaptic mechanisms (Zucker, 1973; Hirst et al., 1981; Hess et al., 1987; see Redman, 1990, for a revicw). Such factors arc likely to be important in synaptic transmission during geniculocortical activation by suprathreshold visual stimulation and may be limited by the morphological changes that we observed in the smaller boutons of $\mathrm{D}$ axons.

A combination of the reduction in the number of synapses per bouton and a reduction in arbor size suggests that the $D$ arborizations contribute fewer synapses in total than the ND axons. However, for single axons the density of the D boutons was higher than that of the ND boutons (see Fig. 7), which should compensate to some degree for changes in synaptic organization that favor the ND axons. Previous evidence from our laboratories showed that each arbor makes no more than one to eight synapses on any single postsynaptic neuron (Freund et al., 1985b; Friedlander and Martin, 1989). This constitutes a few percent of the total synaptic input of several hundred synapses from the $\mathrm{LGN}_{\mathrm{d}}$ that any single ncuron rccives on average. We have also previously estimated that every point in layer 4 of area 18 of normal adult cortex could potentially be contacted by approximately $4000 \mathrm{LGN}_{\mathrm{d}} \mathrm{Y}$-axons because of the overlap of single arbors (Friedlander and Martin, 1989). It follows that even a considerable reduction in the extent of the arbors, and therefore the overlap or coverage, need not necessarily result in a significant loss of synaptic input to a single cortical neuron as long as the numbers of synapses were not significantly reduced as well. The coverage for $\mathrm{D}$ axons drops to approximately $3000 \mathrm{LGN}_{\mathrm{d}} \mathrm{Y}$-axons (similar to that in kitten; Friedlander and Martin, 1989). Thus, there are sufficient D axons to provide considerable input to the postsynaptic neurons, if the total number of synapses is not also reduced. The target distribution of the geniculocortical boutons may also be a significant factor in the altered function of cortical neurons. The ND axons form a higher proportion of thcir synapses on dendritic shafts than either $\mathrm{D}$ or $\mathrm{N}$ axons. These shaft synapses may be more potent than spine synapses because they are larger than spine synapses and because they bypass any limitations on the magnitude of the synaptic current that might be imposed by the spine (see Douglas and Martin, 1990). Moreover, such synaptic rearrangement may have adverse functional consequences. It has been observed that cortical neurons driven from the ND eye in MDs sometimes respond to visual stimuli with reduced specificity (Shatz and Stryker, 1978; Friedlander, Martin, and Wassenhove-McCarthy, unpublished observations). Since more ND geniculocortical input bypasses the spines of cortical neurons, the specificity attributed to spatial and temporal isolation of various inputs may be reduced. Thus, our data support the synaptic rearrangement hypothesis as it confers stronger ocular dominance but potentially some loss in speci- ficity to the nondeprived eye. A possible functional manifestation of such a synaptic rearrangement is a compromise in visual abilities through the nondeprived eye of amblyopes. Such an observation has been made in humans with monocular pattern-vision deprivation due to congenital cataracts (Lewis et al., 1989).

\section{Binocular competition?}

The longstanding model for the development and plasticity of ocular dominance columns is that of synaptic competition (Wiesel and Hubel, 1965; Guillery and Stelzner, 1970; Hubel and Wiesel, 1970; Sherman et al., 1975). In this model, it is hypothesized that the two sets of afferents driven by the left and right eye, respectively, compete for the same synaptic territory. Under conditions in which one set of axons is placed at a disadvantage, as in MD, their synaptic sites are taken over by the advantaged competing set of axons. Our data suggest that this model may be too simple. While it may be that some D synaptic sites are taken over by ND synapses, it is clear that the ND terminals induce synapses at ectopic sites on the dendritic shafts. These shaft synapses are not present in such high proportions during development or in the adult; they are novel. One interpretation of this observation is that these shaft synapses are the result of axonal sprouting, induced by some trophic factor(s) during MD when all other appropriate sites on the neuron are already occupied by synapses. The sprouting axons then induce synapses at positions on the dendrites that seem to be of second preference in the normal animal (spines forming about 70-80\% of targets in normals). Another interpretation should also be considered: one major developmental change in dendritic morphology described to date between the neonate and adult is a loss of dendritic spines (Boothe et al., 1979). If these disappearing spines have synapses on them from the geniculocortical axons, then the synapse may remain on ND axons even when the spine reverts to shaft membrane. Alternatively, these terminals may invade dendritic shaft sites vacated by intracortical axons.

The model generally used to illustrate the possible synaptic events underlying the development and plasticity of ocular dominance columns in the visual cortex is that of the neuromuscular junction, which has a developmental stage of polyneuronal innervation followed by synapse elimination through competition (Van Essen, 1982). This may not be a fully accurate model for the cortex, however. Unlike the neuromuscular junction, a feature of adult cortical neurons is that they normally retain a polysynaptic innervation from many different geniculocortical axons (Freund et al., 1985a,b; Fricdlander and Martin, 1989). It is also difficult to account for the induction of novel synaptic sites based on the hypothesis of competition for synaptic sites. Hebbian synaptic mechanisms (Hebb, 1949; Stent, 1973; Bienenstock et al., 1982; Reiter and Stryker, 1988; Fregnac and Schulz, 1990) have been posited to account for the subsequent strengthening and weakening of geniculocortical synapses that are correlated and anticorrelated with depolarization of their target neurons, respectively. Although such mechanisms may account for rapid functional alterations in synaptic efficacy (Fregnac et al., 1990), our results indicate that long-term MD results in a profound morphological alteration in the structure of these synapses. Thus, our results raise two fundamental questions. First, what is the linking mechanism whereby rapid alterations in synaptic efficacy, such as those exhibited by Hebb synapses, are translated into long-term structural changes in 
synapses? These structural changes occur at the macroscopic level in terms of the extent of entire thalamocortical axonal arborizations and at the microscopic level in terms of altered synaptic ultrastructure. Second, what is the nature of the competition between the D and ND terminals? Might there not be processes affecting $\mathrm{D}$ axons that are independent and different from those affecting ND axons?

\section{State of $M D$ cortex-retraction versus failure to grow}

The mechanisms underlying MD have been suggested alternatively to be an example of neoteny for the deprived eye pathway or a degenerative state. Our results support some aspects of both mechanisms but generally favor the former. The smaller than normal arborizations of the $D$ axons are reminiscent of the normal kitten $\mathrm{Y}$-arbors in area 18 (Friedlander and Martin, 1989). In previous studies on development of ocular dominance columns (LeVay et al., 1978, 1980) in area 17, it has been suggested that the arbors might initially be large and homogeneous during development and retract and remodel to form adult columns (implying that the MD state is a degenerated one of overretraction). However, in area 18 of young kittens (Milleret et al., 1989), it has been shown that instead of more mixing of input from the two eyes onto single cortical cells as compared to the adult, less mixing occurs. Thus, the implication of this finding and of direct structural studies of the development of individual geniculocortical axons (Friedlander and Martin, 1989) is that the postnatal period is characterized by progressive expansion of $Y$-axon arbors in area 18 , not the retraction suggested for area 17 (LeVay et al., 1978). This expansion is also indicative of the postnatal development of $\mathrm{Y}$-type retinogeniculate axons (Sur et al., 1984; Friedlander et al., 1985) as well as the dendritic arbors of geniculate $\mathrm{Y}$-cells (Friedlander, 1982; Tootle and Friedlander, 1986) and retinal Y-cells (Dann et al., 1988; Ramoa et al., 1988). Thus, the entire retinogeniculocortical $Y$-pathway is characterized by postnatal expansion (Friedlander and Tootle, 1990). MD may simply arrest the development of the immature smaller geniculocortical axon arbors and smaller boutons of the $\mathrm{D}$ axons that do not provide efficacious drive to their targets and, at the same time, accelerate or extend the normal growth process for ND axon arborizations. Moreover, the ultrastructural features of the geniculocortical synapses of D axons are very similar to those for normal kitten axons at the peak of the critical period of development (Friedlander and Martin, 1989). The boutons are smaller, higher in density, and have fewer synaptic contacts (primarily on spines), including a significant fraction of boutons that make no contacts. Thus, our data support the failure-to-grow hypothesis. The fact that such growth does not proceed normally in the MD if the deprived eye is later opened is probably due to the lack of a suitable growth environment in the cortex that exists only transiently during the critical period for development of binocular cortical function.

\section{References}

Adams JC (1981) Heavy metal intensification of DAB based HRP reaction product. J Histochem Cytochem 29:775.

Bienenstock E, Cooper LN, Munro P (1982) Theory for the development of neuron selectivity: orientation specificity and binocular interaction in visual cortex. J Neurosci 2:23-48.

Boothe RG, Greenough WT, Lund JS, Wrege K (1979) A quantitative investigation of spine and dendritic development of neurons in visual cortex (area 17) of Macaca nemestrina monkeys. J Comp Neurol 186: 473-490.

Burchfiel JL, Duffy FH (1981) Role of intracortical inhibition in de- privation amblyopia: reversal by microiontophoretic bicuculline. Brain Res 206:479-484.

Dann F, Buhl EH, Peichl L (1988) Postnatal dendritic maturation of alpha and beta ganglion cells in the cat retina. $J$ Neurosci 8:14851499

Dews PB, Wiesel TN (1970) Consequences of monocular deprivation on visual behavior in kittens. J Physiol (Lond) 206:437-455.

Douglas RJ, Martin KAC (1990) Neocortex. In: The synaptic organization of the brain, 3d ed (Shepherd GM, ed), pp 389-438. Oxford: Oxford UP.

Duffy FL, Snodgrass SR, Burchfiel JL, Conway JL (1976) Bicuculline reversal of deprivation on amblyopia in the cat. Nature 260:256-257.

Fifkova E (1970) Effect of unilateral deprivation on visual centers in rats. J Comp Neurol 140:431-438.

Freeman RD, Ohzawa I (1988) Monocular deprived cats: binocular test of cortical cells reveal functional connections from the deprived eye. J Neurosci 8:2491-2506.

Fregnac Y, Imbert M (1984) Development of neuronal selectivity in primary visual cortex of cat. Physiol Rev 64:325-434.

Fregnac Y, Schulz D (1990) Models of synaptic plasticity and cellular analogs of learning in the developing and adult visual cortex. In: Advances in neural and behavioral development, Vol 4 (Casagrande V, Shinkman P, eds). New Jersey: Neural Ablex.

Fregnac Y, Smith D, Friedlander MJ (1990) Postsynaptic membrane potential regulates synaptic potentiation and depression in visual cortical neurons. Soc Neurosci Abstr 16:798.

Freund TF, Martin KAC, Whitteridge D (1985a) Innervation of cat visual areas 17 and 18 by physiologically identified $X$ - and Y-type thalamic afferents. I. Arborization patterns and quantitative distribution of postsynaptic elements. J Comp Neurol 242:263-274.

Freund TF, Martin KAC, Somogyi P, Whitteridge D (1985b) Innervation of cat visual areas 17 and 18 by physiologically identified $X$ and $Y$-type thalamic afferents. II. Identification of postsynaptic targets by GABA immunocytochemistry and Golgi impregnation. J Comp Neurol 242:275-291.

Friedlander MJ (1982) Structure of physiologically classified neurons in the kitten dorsal lateral geniculate nucleus. Nature 200:180-183.

Friedlander MJ, Martin KAC (1989) Development of Y-axon innervation of cortical area 18 in the cat. J Physiol (Lond) 416:183-213.

Friedlander MJ, Tootle JS (1990) Postnatal anatomical and physiological development of the visual system. In: Development of sensory systems in mammals (Coleman JR, ed), pp 61-124. New York: Wiley.

Friedlander MI, Lin C-S, Stanford LR, Sherman SM (1981) Morphology of functionally identified neurons in the dorsal lateral geniculate nucleus of cat. J Neurophysiol 46:80-129.

Friedlander MJ, Stanford LR, Sherman SM (1982) Effects of monocular deprivation on the structure/function relationship of individual neurons in the cat's lateral geniculate nucleus. J Neurosci 2:321-330.

Fricdlander MJ, Martin KAC, Vahlc-Hinz C (1985) The structure of the terminal arborizations of physiologically identified retinal ganglion cell Y-axons in the kitten. J Physiol (Lond) 359:293-313.

Friedlander MJ, Anderson JC, DeHay C, Martin KAC, Nelson JV (1990) Postnatal development of geniculocortical synapses in area 17. Soc Neurosci Abstr 16:1129.

Garey LJ, Pettigrew JD (1974) Ultrastructural changes in kitten visual cortex after environmental modification. Brain Res 66:165-172.

Griffin F, Mitchell DE (1978) The rate of discovery of vision after early MD in kittens. J Physiol (Lond) 274:511-538.

Guillery RW, Stelzner DJ (1970) The differential effects of unilateral eyelid closure on the monocular and binocular segments of the dorsal lateral geniculate nucleus of the cat. J Comp Neurol 139:413-422.

Hanker JS, Yates PE, Metz CB, Rustioni A (1977) A new specific sensitive and non-carcinogenic reagent for the demonstration of horseradish peroxidase [letter]. Histochem J 9:789-792.

Harwerth RS, Crawford MLS, Smith ER III, Boltz RL (1981) Behavioral studies of stimulus deprivation amblyopia in monkeys. Vis Res 21:779-789.

Hebb D (1949) The organization of behavior. New York: Wiley.

Hess G, Kuhnt V, Voronin LL (1987) Quantal analysis of paired pulse facilitation in guinea pig hippocampal slices. Neurosci Lett 77:187192.

Hickey TL, Spear PD, Kratz KE (1977) Quantitative studies of cell size in the cat's dorsal lateral geniculate nucleus following visual deprivation. J Comp Neurol 172:265-282.

Hirst GDS, Redman SJ, Wong K (1981) Post-tetanic potentiation and 
facilitation of synaptic potentials evoked in cat spinal motoneurones. J Physiol (Lond) 321:97-109.

Hubel DH, Wiesel TN (1963) Receptive fields of cells in striate cortex of very young, visually inexperienced kittens. J Neurophysiol 26:994 1002.

Hubel DH, Wiesel TN (1965) Receptive fields and functional architecture in 2 non-striate visual areas (18 and 19) of the cat. J Neurophysiol 28:229-289.

Hubel DH, Wiesel TN (1970) The period of susceptibility to the physiological effects of unilateral eye closure in kittens. J Physiol (Lond) 206:419-436.

Hubel DH, Wiesel TN, LeVay S (1977) Plasticity of ocular dominance columns in monkey striate cortex. Philos Trans R Soc Lond [Biol] 278:377-409.

Kalil R (1980) A quantitative study of the effects of monocular enucleation and deprivation on cell grov/th in the dorsal lateral geniculate nucleus of the cat. J Comp Neuro! 189:483-524.

Kato H, Kawaguchi S, Yamamoto T, Samejima A, Miyato H (1983) Postnatal development of the geniculocortical projection in the cat: electrophysiological and morphological studies. Exp Brain Res 51: 65-72.

Kossut M, Thompson ID, Blakemore C (1983) Ocular dominance columns in cat striate cortex and effects of monocular deprivation: a 2-deoxyglucose study. Acta Neurol Exp 43:273-282.

Kratz KE, Spear PD, Smith DC (1976) Postcritical period reversal of effects of monocular deprivation on striate cortex cells in the cat. $J$ Neurophysiol 39:501-511

Leigh RJ, Thurston SE, Tomsak RL, Grossman GE, Lanska DJ (1989) Effect of monocular visual loss upon stability of gaze. Invest Ophthalmol Vis Sci 30:288-292.

LeVay S, Stryker MP, Shatz CJ (1978) Ocular dominance columns and their development in layer IV of the cat's visual cortex: a quantitative study. J Comp Neurol 179:223-244.

LeVay S, Wiesel TN, Hubel DH (1980) The development of ocular dominance columns in normal and visually deprived monkeys. $J$ Comp Neurol 191:1-51.

Lewis TL, Maurer D, Tytla ME, Bowering E, Brent HP (1989) Vision in the "normal" eye of children treated for unilateral congenital cataract. Invest Ophthalmol Vis Sci [Suppl] 30:376.

Lund JS, Henry GH, McQueen CL, Harvey AR (1979) Anatomical organization of the primary visual cortex (area 17) of the cat. A comparison with area 17 of the macaque monkey. J Comp Neurol 184:599-618.

McCarthy D, Coleman LA, Martin KAC, Friedlander MJ (1989) Monocular deprivation affects $Y$-cell geniculocortical synapses in cat area 18. Invest Ophthalmol Vis Sci 30:30.

Milleret C, Gary-Bobo E, Buisseret P (1989) Comparative development of cell properties in cortical area 18 of normal and dark-reared kittens. Exp Brain Res 71:8-20.

Mioche L, Singer W (1989) Chronic recordings from single sites of kitten striate cortex during experience-dependent modifications of receptive-field properties. J Neurophysiol 62:185-197.

Mitchell DE, Timney BN (1981) In: Analysis of visual behavior (Ingle DJ, Goodale MA, Mansfield RJ, eds), pp 483-523. Cambridge, MA: MIT Press.

Mitchell DE, Murphy KM, Kaye MG (1984) Labile nature of the visual recovery promoted by reverse occlusion in monocularly deprived kittens. Proc Natl Acad Sci USA 81:286-288.

Mitzdorf U, Singer W (1980) Monocular activation of visual cortex in normal and monocularly deprived cats: an analysis of evoked potentials. J Physiol (Lond) 304:203-220.

Mower GD, Christen WG, Burchfiel JL, Duffy FH (1984) Microiontophoretic bicuculline restores binocular responses to visual cortical neurons in strabismic cats. Brain Res 309:168-172.

O'Leary JL (1941) Structure of the area striata of the cat. J Comp Neurol 75:131-161.

Olson CR, Freeman RD (1975) Progressive changes in kitten striate cortex during monocular vision. J Neurophysiol 38:26-32.

Purpura DP, Shofer RJ, Scarff T (1965) Properties of synaptic activities and spike potentials of neurons in immature neocortex. J Neurophysiol 28:925-942.
Ramoa AS, Campbell GA, Shatz CJ (1988) Dendritic growth and remodeling of cat retinal ganglion cells during fetal and postnatal development. J Neurosci 8:4239-4261.

Redman S (1990) Quantal analysis of synaptic potentials in neurons of the central nervous system. Physiol Rev 70:165-198.

Reiter HO, Stryker MP (1988) Neural plasticity without postsynaptic action potentials: less active inputs become dominant when kitten visual cortical cells are pharmacologically inhibited. Proc Natl Acad Sci USA 85:3623-3627.

Schwartz ML, Rothblat LA (1980) Long-lasting behavioral and dendritic spine deficits in the monocularly deprived albino rat. Exp Neurol 68:136-146.

Shatz CJ, Stryker MP (1978) Ocular dominance in layer IV of the cat's visual cortex and the effects of monocular deprivation. J Physiol (Lond) 281:267-283.

Sherman SM, Guillery RW (1976) Behavioral studies of binocular competition in cats. Vision Res 16:1479-1481.

Sherman SM, Spear PD (1982) Organization of visual pathways in normal and visually deprived cats. Physiol Rev 62:738-855.

Sherman SM, Stone J (1973) Physiological normality of the retina in visually deprived cats. Brain Res 40:224-230.

Sherman SM, Guillery RW, Kaas JG, Sanderson KJ (1975) Behavioral, electrophysiological and morphological studies of binocular competition in the development of the geniculocortical pathway in cats. J Comp Neurol 158:1-18.

Singer W (1978) The effect of monocular deprivation on cat parastriate cortex: asymmetry between crossed and uncrossed pathways. Brain Res 157:351-355.

Stent G (1973) A physiological mechanism for Hebb's postulate of learning. Proc Natl Acad Sci USA 70:997-1001.

Sur M, Humphrey AL, Sherman SM (1982) Monocular deprivation affects retinogeniculate terminations in cats. Nature 300:183-185.

Sur M, Weller R, Sherman SM (1984) Development of X-and Y-cell retinogeniculate terminations in cats. Nature 310:246-248.

Tieman SB (1984) Effects of monocular deprivation on geniculocortical synapses in the cat. J Comp Neurol 222:166-176.

Tieman SB (1985) The anatomy of geniculocortical connections in monocular deprived cats. Cell Mol Neurobiol 5:35-45.

Tootle JS, Friedlander MJ (1986) Postnatal development of receptive field surround inhibition in kitten dorsal lateral geniculate nucleus. J Neurophysiol 56:523-541.

Tootle JS, Friedlander MJ (1989) Postnatal development of the spatial contrast sensitivity of $\mathrm{X}$ - and $\mathrm{Y}$-cells in the kitten retinogeniculate pathway. J Neurosci 9:1325-1340.

Trotter Y, Fregnac Y, Buisseret P (1987) The period of susceptibility of visual cortical binocularity to unilateral proprioceptive deafferentation of extraocular muscles. J Neurophysiol 58:795-815.

Tsumoto T, Suda K (1978) Evidence for excitatory connections from the deprived eye to the visual cortex in monocularly deprived kittens. Brain Res 153:150-156.

Tumosa N, Tieman SB, Tieman DG (1989) Binocular competition affects the pattern and intensity of ocular activation columns in the visual cortex of cats. Visual Neurosci 2:391-407.

Van Essen D (1982) Neuromuscular synapse elimination. In: Neuronal development (Spitzer HC, ed), pp 333-376. New York: Plenum.

Van Hof-Van Duin J (1976) Early and permanent effects of monocular deprivation of pattern discrimination and visuomotor behavior in cats. Brain Res 111:261-276.

Wiesel TN (1982) Postnatal development of the visual cortex and the influence of environment. Nature 299:583-591.

Wiesel TN, Hubel DH (1963) Single-cell responses in striate cortex of kittens deprived of vision in one eye. J Neurophysiol 26:10031017.

Wiesel TN, Hubel DH (1965) Comparison of the effects of unilateral and bilateral closure on cortical unit responses in kittens. J Neurophysiol 28:1029-1040.

Wong-Riley MT (1979) Changes in the visual system of monocularly sutured or enucleated cats demonstrable with cytochrome oxidase histochemistry. Brain Res 171:11-28.

Zucker RS (1973) Changes in the statistics of transmitter release during facilitation. J Physiol (Lond) 229:787-810. 